\title{
Asian monsoon amplifies semi-direct effect of biomass burning aerosols on low cloud formation
}

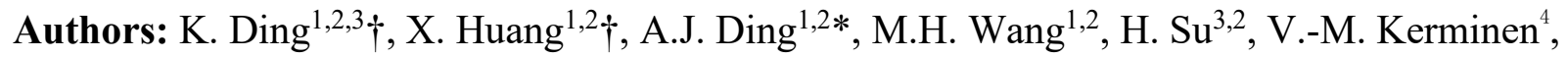
T. Petäjä ${ }^{4}, 1$, Z. M. Tan ${ }^{1,2}$, Z. L. Wang ${ }^{1}$, D.R. Zhou ${ }^{1,2}$, J. Sun ${ }^{1,2}$, H. Liao ${ }^{5}$, H.J. Wang ${ }^{5}$, K. Carslaw ${ }^{7}$,

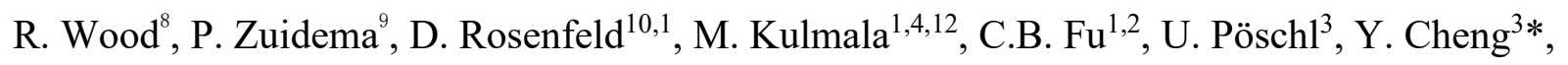
M. O. Andreae $3,11,13$

\section{Affiliations:}

${ }^{1}$ Joint International Research Laboratory of Atmospheric and Earth System Sciences, School of Atmospheric Sciences, Nanjing University, Nanjing, 210023, China

${ }^{2}$ Jiangsu Provincial Collaborative Innovation Center of Climate Change, Nanjing, China

${ }^{3}$ Max Planck Institute for Chemistry, Mainz, Germany

${ }^{4}$ Institute for Atmospheric and Earth System Research (INAR)/Physics, University of Helsinki, Finland

${ }^{5}$ School of Environment, Nanjing University of Information and Science Technology, Nanjing ${ }^{6}$ School of Atmospheric Sciences, Nanjing University of Information and Science Technology, Nanjing

${ }^{7}$ Institute for Climate and Atmospheric Science, School of Earth and Environment, University of Leeds, UK

${ }^{8}$ Department of Atmospheric Sciences, University of Washington, Seattle, USA

${ }^{9}$ Rosenstiel School of Marine and Atmospheric Sciences, University of Miami, FL, USA

${ }^{10}$ Institute of Earth Sciences, The Hebrew University of Jerusalem, Jerusalem, 91904, Israel

${ }^{11}$ Scripps Institution of Oceanography, University of California San Diego, La Jolla, CA, USA

${ }^{12}$ Aerosol and Haze Laboratory, Beijing Advanced Innovation Center for Soft Matter Science and Engineering, Beijing University of Chemical Technology, Beijing, China

${ }^{13}$ Department of Geology and Geophysics, King Saud University, Riyadh, Saudi Arabia

*Correspondence to: dingaj@nju.edu.cn (A.D.), yafang.cheng@mpic.de (Y.C.)

$\dagger \mathrm{K}$. Ding and X. Huang contributed equally to this work. 


\begin{abstract}
Low clouds play a key role in the Earth-atmosphere energy balance and influence agricultural production and solar-power generation. Smoke aloft has been found to enhance marine stratocumulus over the Southeast Atlantic in austral spring through aerosol-cloud interactions, but its role in regions with strong human activities and complex monsoon circulation remains unclear. Here we show that biomass burning aerosols aloft strongly increase the low-cloud coverage over both land and ocean in subtropical southeastern Asia. The degree of this enhancement and its spatial extent are comparable to that in the Southeast Atlantic, even though biomass burning emissions in Southeast Asia are only one-third of those in Southern Africa. Our results indicate that a coupling of aerosol-cloud-boundary-layer feedback with the monsoon is the main reason for the strong semi-direct effect and enhanced low-cloud formation in Asia.
\end{abstract}

\title{
One Sentence Summary:
}

Smoke aloft strongly enhances low-cloud formation in southeastern Asia by an aerosol-cloudboundary-layer feedback coupled with the monsoon circulation.

\section{Main Text:}

Low clouds, including stratocumulus, cumulus, and stratus, cover about $30 \%$ of the globe and play important roles in the Earth system because of their strong influence on the planetary albedo and the energy balance of the Earth $(1,2)$. By reducing solar radiation reaching the surface, persistent low clouds over land have negative impacts on agricultural production and solarpower generation $(3,4)$. Therefore, understanding the factors governing low cloud cover is not only critical for regional weather forecasting and global climate prediction $(3,5-7)$ but also important for their socioeconomic effects. Modeling studies have suggested that absorbing aerosols from sources like biomass burning (BB) can enhance the formation and evolution of low clouds, especially over the Southeast Atlantic and adjacent parts of Africa (Atlantic-Africa) in austral spring (8-11). However, in East Asia, a region that combines high population density, high social and economic relevance (fig. S1), and high levels of air pollution driving aerosol-climate interactions (12-14), a quantitative understanding of these effects on low clouds (fig. S2) is still missing, especially from a climatological perspective. By analyzing 16-year satellite observational and meteorological reanalysis data together with numerical modeling results, we find that the efficiency of low-cloud enhancement by the smoke aloft is particularly strong in Asia, with the low cloud fraction increasing by a factor of three more than that in the Southeast Atlantic. The amplified aerosol-cloud interactions are mainly caused by the smoke's coupling with planetary boundary layer (PBL) feedbacks and the Asian winter monsoon.

We adopted an observation minus model reanalysis (denoted as OMR) approach, combining MODIS satellite observational data with ECMWF (European Centre for Medium-Range Weather Forecast) Interim Re-Analysis (ERA-Interim) data (Sects. S1-S3 in Supplementary Materials). 
Since the ERA-Interim model does not explicitly consider the effects of aerosols (15), the difference between observations and models reflects the impact of un-resolved processes, such as aerosol-cloud interactions (Sect. S1) $(12,16)$. Figures 1A and 1B show the 16-year averaged OMR difference in cloud fraction during the BB seasons in southeastern Asia (March) and AtlanticAfrica (August), two typical regions of the globe with strong BB and cloud-induced outgoing short-wave radiation (figs. S3-S4). The high OMR values are mostly distributed along the coastal region and the oceanic area off southern China and the Atlantic off southwestern Africa (as marked by blue boxes in fig. S5, A and B), covering areas over $3000 \times 1000 \mathrm{~km}^{2}$. The cloud-top pressure (figs. S5E and S5F) shows that the clouds in these areas are mostly low clouds. Although BB emission in southeastern Asia in March is only $\sim 30 \%$ of that in southern Africa in August (S4, fig. S4B and table S4), the cloud cover in the main transport pathways of the smoke shows a similar enhancement (over 30\%) in both cases (Figs. 1A and 1B, and fig. S5), suggesting a much stronger aerosol effect on low cloud formation in southeastern Asia.

The stronger aerosol effect in southeastern Asia is not only evident from the climatological average but is also resolved at different tempo-spatial scales. As shown in Fig. 1C and fig. S6, the inter-annual variability of OMRs follows that of the aerosol optical depth (AOD), BB emissions, and CO column density in the middle troposphere, with a better correlation in Asia than in Africa. At the seasonal scale, a synchronized increase of cloud fraction in the region downwind of the BB sources (fig. S5C) corresponds to the BB emission peak in March (fig. S7). Such positive correlations also hold for the monthly- and daily averaged data (Fig. 1D), as well as at the synoptic scale (fig. S8), in Asia. The averaged vertical distribution of CALIPSO aerosol extinction and cloud occurrence for high and low AOD years also suggest a stronger vertical linkage of smoke aloft and low-cloud enhancement below in Asia (Figs. 2A and 2B) than in the AtlanticAfrica region (fig. S9 and fig. S10). In Asia, the low-cloud enhancement is mainly located beneath the plume transport altitude around $3 \mathrm{~km}$ (Fig. 2 and fig. S11) (17), with cloud top heights of approximately $2.5 \mathrm{~km}$ above sea level over the lee side of the plateau, i.e., the Beibu Bay (Fig. 2A), and cloud top heights of approximately $1.5 \mathrm{~km}$ above the flatlands and ocean, i.e., the Taiwan Strait (Fig. 2B), a region with very strong low-cloud enhancement (Fig. 1A). In the AfricaAtlantic region, the signal of low-cloud enhancement at the interannual scale is, in contrast, much weaker (figs. S10, S6) in terms of both cloud fraction and cloud thickness.

Over the Beibu Bay, a strong increase in cloud occurrence (50-60\%) exists between the altitudes of 1 and $2 \mathrm{~km}$ in high BB pollution years (Fig. 2A). In this region, the low-cloud enhancement exists not only over ocean but also over land areas (Fig. 1A), which is also one of the distinctive features in subtropical Asia in contrast to Atlantic-Africa (fig. S12). In the latter region (Fig. 1B), low clouds are enhanced over the Atlantic but reduced on the African continent, with coastal lines as a clear border between the two distinct effects, which have been well documented in previous modelling studies and satellite observations $(5,10-11,18-20)$. The enhancement over 
ocean has been attributed to the semi-direct effect of absorbing aerosols from BB above the marine stratocumulus $(9,21)$. The reduction of cloudiness over land can be explained by the aerosol absorption cloud fraction feedback (AFF) proposed by Koren et al. (22), where surface cooling reduces moisture fluxes and the upper level warming reduces the relative humidity in the cloud layer. This raises the questions: What causes the different response over the land regions between Africa and Asia, and how is this connected to the mechanisms of low-cloud amplification in subtropical Asia?

To understand these underlying mechanisms, we performed numerical simulations with the WRF-Chem model (Weather Research and Forecasting model coupled with Chemistry) for March of four high-AOD years (2004, 2007, 2010 and 2014) and four low-AOD years (2001, 2003, 2005, 2011) in subtropical Asia, as identified in Fig. 1C. (detailed modeling configurations are given in Sect. S5 and tables S1-S3). The difference in cloud fractions between simulations with and without $\mathrm{BB}$ emissions is calculated and then compared with the results from OMRs. Our model simulations successfully reproduce the aerosol-cloud interactions in Asia for both the horizontal distribution (Fig. 3A) and vertical cross-section (Fig. 3B). Note that, besides the BB emissions, we also tested the influence of other sources (e.g., fossil fuel combustion emissions) and of aerosol-cloud interaction. The fossil fuel sources and the aerosol-cloud interaction have negligible effects on the cloud cover, confirming the dominant role of BB smoke's radiative effect on the low-cloud enhancement in subtropical Asia (see fig. S13).

As shown in Fig. 3B, a substantial heating by absorbing aerosols like BC (on average more than $1.0 \mathrm{~K}$ difference between the runs with BB on/off) (23-25) exists in the area downwind (about $1000 \mathrm{~km}$ away) of the BB source region, accompanied by a significant cooling at lower altitudes, particularly over the land area on the lee side of the plateau (Fig. 3B). Accordingly, the liquid water contents below the elevated plume, i.e., between the altitudes of 0.5 and $2 \mathrm{~km}$, are significantly enhanced in the dimming region and are transported further upwards by the converging circulations of the monsoon and then eastward by the upper level westerlies, resulting in a substantial enhancement in cloud (over 60\%) between the altitudes of 1 and $2 \mathrm{~km}$ in the downwind region (Fig. 3B). In contrast, for the low-AOD years, with less influence of the BB emissions from Southeast Asia, the enhancement of cloud in subtropical Asia is very weak (Figs. 3C3D).

The key role of aerosol-cloud-PBL feedbacks in the strong response over the land area bordering Beibu Bay can be clearly demonstrated by the simulation and detailed analyses of a typical case on 13 March 2004. On that day, the upper-air warming reached about $5 \mathrm{~K}$ and the surface cooling reached about $10 \mathrm{~K}$ at Nanning in Guangxi, China (fig. S14A). The simulations with Aerosol Radiation Interaction (ARI) on/off clearly demonstrate substantial low-cloud enhancement by the smoke, showing excellent agreement of the diurnal cycle of low clouds in the ARIon case compared to both satellite and ground-based observations (fig. S14B). A statistical anal- 
ysis of the 8 highest and 8 lowest ARI cases (according to OMR surface air temperature) in Nanning during March 2004 suggests a significant difference in the air temperature profile caused by the aerosol-cloud-PBL interaction (fig. S15). The WRF-Chem simulations show a substantial low cloud enhancement by the smoke aloft, especially in the afternoon of the days with higher ARI (fig. S14, C and D).

The key to explaining the amplification of low-cloud enhancement in subtropical Asia is the mechanism by which the moisture within the middle and upper PBL in the ARI-induced dimming region over land is maintained. Over the Amazon (22), the BB smoke causes a decreased cloud amount over land due to the reduced moisture fluxes associated with surface cooling and reduced relative humidity of the cloud layer. In contrast, in subtropical Asia, the Asian winter monsoon drives an overall clockwise large-scale circulation along the coastal waters in spring (fig. S1B), which brings large amounts of water vapor from the ocean into the dimming region on the lee side of the plateau with intense BB activities (Sect. S6, fig. S16C). The air masses become saturated in the middle and upper PBL by ARI-induced cooling (Fig. 3B, fig. S14C), causing enhanced low cloud over land, which extends over both land and the oceanic area downwind. Here, the radiative heating of smoke above the clouds creates a strong inversion that is conducive to the formation of extensive shallow clouds below it, which are maintained by radiative cooling over land associated with the transport of water vapor by the monsoon circulation (Fig. 4). This mechanism for Asia is different from the traditional understanding of the aerosol-cloud feedback caused by the semi-direct effect of smoke over the southeast Atlantic, where the moisture outflow from the continent is primarily above the low cloud layer $(11,26)$ (fig. S17). It is a synergetic effect of aerosol-cloud-PBL feedbacks and the large-scale monsoon circulation. The semidirect effect of smoke aerosols above clouds, the large-scale upper-PBL strong inversion, a substantial dimming within the land PBL, together with the transport of water vapor by the monsoon circulation amplify the low-cloud enhancement over the land and the downwind ocean area in subtropical southeastern Asia (Fig. 4), resulting in a much more efficient low cloud enhancement than in the Africa case (fig. S17).

Our results demonstrate that aerosol-radiation interaction dominates the springtime lowcloud enhancement in southeastern Asia. The coupling of above-cloud heating and surface dimming manifests itself in the climatology of OMR air temperature bias for high AOD days in spring (fig. S18). Given that low clouds substantially influence radiation transfer, the large-scale low-cloud enhancement documented here will strongly influence the regional climate and weather conditions (27-30). In subtropical Asia, the region with significant low-cloud enhancement (i.e., with OMR values $>25 \%$ in Fig. 1A) covers a land area of about half a million $\mathrm{km}^{2}$ with a population greater than 270 million. Given the direct impacts the clouds over land have on human activities such as solar-energy generation and agricultural production, the mechanism reported here is important for sustainability in this large and important region and needs to be included in future forecast and assessment models. 


\section{References}

1. S.A. Klein, D.L. Hartmann, The seasonal cycle of low stratiform clouds. J. Climate 6, 15871606 (1993).

2. $\quad$ R. Wood, Stratocumulus clouds, Mon. Weather Rev. 140, 2373-2423 (2012).

3. M. Ahlgrimm, R. Forbes, The impact of low clouds on surface shortwave radiation in the ECMWF model. Mon. Weath. Rev. 140, 3783-3794 (2012).

4. C. Köhler et al., Critical weather situations for renewable energies - Part B: Low stratus risk for solar power, Renew. Energ. 101, 794-803 (2017).

5. A.A. Adebiyi, P. Zuidema, Low cloud cover sensitivity to biomass-burning aerosols and meteorology over the Southeast Atlantic, J. Climate 31, 4329-4346 (2018).

6. A. Keil, J.M. Haywood, Solar radiative forcing by biomass burning aerosol particles during SAFARI 2000: A case study based on measured aerosol and cloud properties, J. Geophys. Res. 108, D13, 8467 (2003).

7. P. Zuidema, J. Redemann, J. Haywood, R. Wood, S. Piketh, M. Hipondoka, P. Formenti, Smoke and clouds above the Southeast Atlantic- Upcoming field campaigns probe absorbing aerosols impact on climate, Bull. Amer. Metorolog. Soc. 97, 1131-1135 (2016).

8. B.T. Johnson, K.P. Shine, P.M. Forster, The semi-direct aerosol effect: impact of absorbing aerosols on marine stratocumulus, Q. J. Roy. Meteor. Soc. 130, 1407-1422 (2004).

9. D. Koch, A.D. Del Genio, Black carbon semi-direct effects on cloud cover: review and synthesis, Atmos. Chem. Phys. 10, 16, 7685-7696 (2010).

10. N. Sakaeda, R. Wood, R.J. Rasch, Direct and semi-direct aerosol effects of southern African biomass burning aerosol, J. Geophys. Res. 116, D12205 (2011).

11. Z. Lu, X. H. Liu, Z. B. Zhang, C. Zhao, K. Meyer, C. Rajapakshe, C. L. Wu, Z. F. Yang, J. E. Penner, Biomass smoke from southern Africa can significantly enhance the brightness of stratocumulus over the southeastern Atlantic Ocean, Proc. Natl. Acad. Sci. U.S.A. 115, 2924-2929 (2018).

12. H. Gordon, P. R. Field, S. J. Abel, M. Dalvi, D. P. Grosvenor, A.A. Hill, B. T. Johnson, A. K. Milten-berger, M. Yoshioka, K. S. Carslaw, Large simulated radiative effects of smoke in the south-east Atlantic, Atmos. Chem. Phys., 18, 15261-15289 (2018).

13. Z. Q. Li, W. K. M. Lau, V. Ramanathan, G. Wu, Y. Ding, M. G. Manoj, J. Liu, Y. Qian, J. Li, T. Zhou, J. Fan, D. Rosenfeld, Y. Ming, Y. Wang, J. Huang, B. Wang, X. Xu, S. S. Lee, M. Cribb, F. Zhang, X. Yang, C. Zhao, T. Takemura, K. Wang, X. Xia, Y. Yin, H. Zhang, J. Guo, P. M. Zhai, N. Sugimoto, S. S. Babu, G. P. Brasseur, Aerosol and monsoon climate interactions over Asia, Rev. Geophys. 54, 4, 866-929 (2016).

14. Y. Qian, D. Y. Gong, J. W. Fan, L. R. Leung, R. Bennartz, D. L. Chen, W. G. Wang, Heavy pollution suppresses light rain in China: Observations and modeling, J. Geophys. Res. 114, D00K02 (2009).

15. D. P. Dee, S. M. Uppala, A. J. Simmons, P. Berrisford, P. Poli, S. Kobayashi, U. Andrae, M. A. Balmaseda, G. Balsamo, P. Bauer, P. Bechtold, A. C. M. Beljaars, L. van de Berg, J. Bidlot, N. Bormann, C. Delsol, R. Dragani, M. Fuentes, A. J. Geer, L. Haimberger, S. B. Healy, H. Hersbach, E. V. Holm, L. Isaksen, P. Kallberg, M. Kohler, M. Matricardi, A. P. McNally, B. M. Monge-Sanz, J. J. Morcrette, B. K. Park, C. Peubey, P. de Rosnay, C. Tavolato, J. N. 
Thepaut, F. Vitart, The ERA-Interim reanalysis: configuration and performance of the data assimilation system, Q. J. R. Meteorol. Sco. 137, 553-597 (2011).

16. X. Huang, Z. Wang, A. Ding, Impact of Aerosol-PBL Interaction on Haze Pollution: Multiyear Observational Evidences in North China, Geophys. Res. Lett. 45, 8596-8603 (2018).

17. D. J. Jacob, J. H. Crawford, M. M. Kleb, V. S. Connors, R. J. Bendura, J. L. Raper, G. W. Sachse, J. C. Gille, L. Emmons, C. L. Heald, Transport and chemical evolution over the Pacific (TRACE-P) aircraft mission: design, execution, and first results, J. Geophys. Res. 108, 1-19 (2003).

18. A.A. Adebiyi, P. Zuidema, The role of the southern African easterly jet in modifying the southeast Atlantic aerosol and cloud environments, Quart. J. Roy. Meteor. Soc., 142, 1574-1589 (2016).

19. D. Chand, R. Wood, R., T.L. Anderson, S.K. Satheesh, R.J. Charlson, Satellite-derived direct radiative effect of aerosols dependent on cloud cover, Nat. Geosci. 2, 181-184 (2009).

20. S. Das, H. Harshvardhan, H. S. Bian, M. A. Chin, G. Curci, A. P. Protonotariou, T. Mielonen, K. Zhang, H. L. Wang, X. H. Liu, Biomass burning aerosol transport and vertical distribution over the South African-Atlantic region, J. Geophys. Res. 122, 6391-6415 (2017).

21. E.M. Wilcox, Stratocumulus cloud thickening beneath layers of absorbing smoke aerosol, $A t$ mos. Chem. Phys. 10, 11769-11777 (2010).

22. I. Koren, J. V. Martins, L.A. Remer, H. Afargan, Smoke invigoration versus Inhibition of clouds over the Amazon, Science 321, 946-949 (2008).

23. S. Menon, J. Hansen, L. Nazarenko, Y. Luo, Climate effects of black carbon aerosols in China and India, Science 297, 2250-2253 (2002).

24. T. C. Bond, S. J. Doherty, D. W. Fahey, P. M. Forster, T. Berntsen, B. J. DeAngelo, M. G. Flanner, S. Ghan, B. Karcher, D. Koch, S. Kinne, Y. Kondo, P. K. Quinn, M. C. Sarofim, M. G. Schultz, M. Schulz, C. Venkataraman, H. Zhang, S. Zhang, N. Bellouin, S. K. Guttikunda, P. K. Hopke, M. Z. Jacobson, J. W. Kaiser, Z. Klimont, U. Lohmann, J. P. Schwarz, D. Shindell, T. Storelvmo, S. G. Warren, C. S. Zender, Bounding the role of black carbon in the climate system: A scientific assessment. J. Geophys. Res. 118, 5380-5552 (2013).

25. A. J. Ding, X. Huang, W. Nie, J. N. Sun, V. M. Kerminen, T. Petaja, H. Su, Y. F. Cheng, X. Q. Yang, M. H. Wang, X. G. Chi, J. P. Wang, A. Virkkula, W. D. Guo, J. Yuan, S. Y. Wang, R. J. Zhang, Y. F. Wu, Y. Song, T. Zhu, S. Zilitinkevich, M. Kulmala, C. B. Fu, Enhanced haze pollution by black carbon in megacities in China, Enhanced haze pollution by black carbon in megacities in China, Geophys. Res. Lett. 43, 2873-2879 (2016).

26. A. A. Adebiyi, P. Zuidema, S. J. Abel, The Convolution of Dynamics and Moisture with the Presence of Shortwave Absorbing Aerosols over the Southeast Atlantic. J. Clim. 28, 19972024 (2015).

27. K.M. Lau, M.K. Kim, K.M. Kim, Asian summer monsoon anomalies induced by aerosol direct forcing: the role of the Tibetan Plateau, Clim. Dyn. 26, 855-864 (2006).

28. N. H. Lin, A. M. Sayer, S. H. Wang, A. M. Loftus, T. C. Hsiao, G. R. Sheu, N. C. Hsu, S. C. Tsay, S. Chantara, Interactions between biomass-burning aerosols and clouds over Southeast Asia: Current status, challenges, and perspectives, Environ. Pollut. 195, 292-307 (2014). 
29. V. Ramanathan, F. Li, M. V. Ramana, P. S. Praveen, D. Kim, C. E. Corrigan, H. Nguyen, E. A. Stone, J. J. Schauer, G. R. Carmichael, B. Adhikary, S. C. Yoon, Atmospheric brown clouds: hemispherical and regional variations in long range transport, absorption and radiative forcing, J. Geophys. Res. 112, D22S21(2007).

30. J. S. Reid, E. J. Hyer, R. S. Johnson, B. N. Holben, R. J. Yokelson, J. L. Zhang, J. R. Campbell, S. A. Christopher, L. Di Girolamo, L. Giglio, R. E. Holz, C. Kearney, J. Miettinen, E. A. Reid, F. J. Turk, J. Wang, P. Xian, G. Y. Zhao, R. Balasubramanian, B. N. Chew, S. Janjai, N. Lagrosas, P. Lestari, N. H. Lin, M. Mahmud, A. X. Nguyen, B. Norris, N. T. K. Oanh, M. Oo, S. V. Salinas, E. J. Welton, S. C. Liew, Observing and understanding the Southeast Asian aerosol system by remote sensing: An initial review and analysis for the Seven Southeast Asian Studies (7SEAS) program, Atmos. Res. 122, 403-468 (2013).

ACKNOWLEDGMENTS: We are grateful to the High-Performance Computing \& Massive Data Center (HPC\&MDC) of School of Atmospheric Science, Nanjing University for doing the numerical calculations in this paper on its Blade cluster system. Funding: The work is supported by National Natural Science Foundation of China (41422504, 91544231 and 41621005), Ministry of Science and Technology of China 10 (2016YFC0200500), and the CSC-China Scholarship Council for joint Ph.D. grant awarded to K. D. This study was partly supported by European Research Council via ATM-GTP 266 (742206), and Academy of Finland Center of Excellence in Atmospheric Sciences (grant number: 272041). Author contributions: A. D., Y. C., and M. A. conceived the overall idea, K. D. and X. H. made most of the analysis and model simulations, A. D. and Y. C. wrote the manuscript with contributions from all authors. Competing interests: The authors have no competing interests. Data and materials availability: The observational data on are available at https://rda.ucar.edu/datasets and https://ladsweb.modaps.eosdis.nasa.gov. Additional data related to the modeling results can be requested from the authors.

\section{Supplementary Materials:}

Materials and Methods

Figures S1-S18

Tables S1-S4

References (1-32) 
A

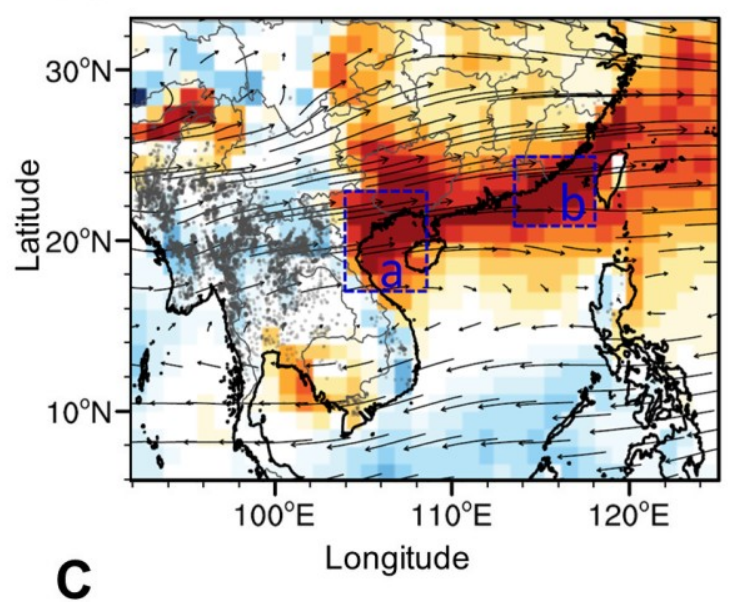

B

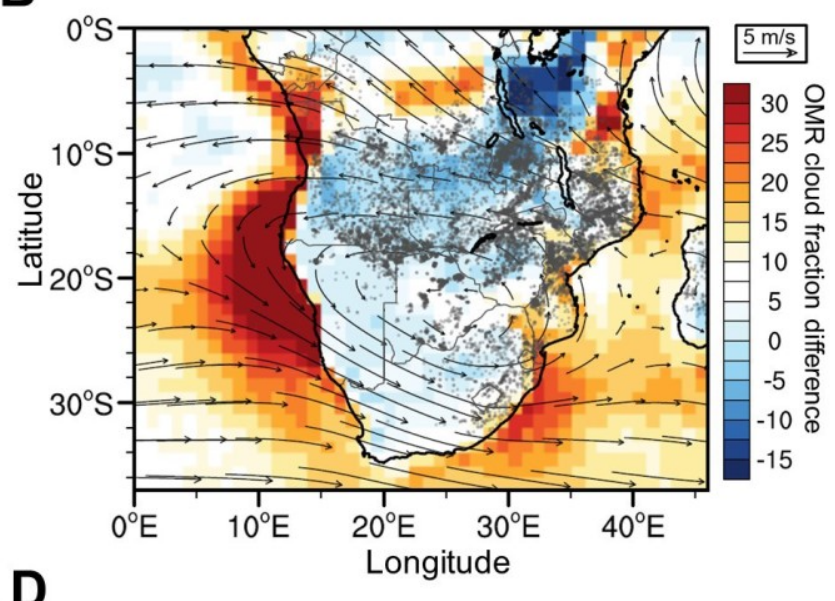

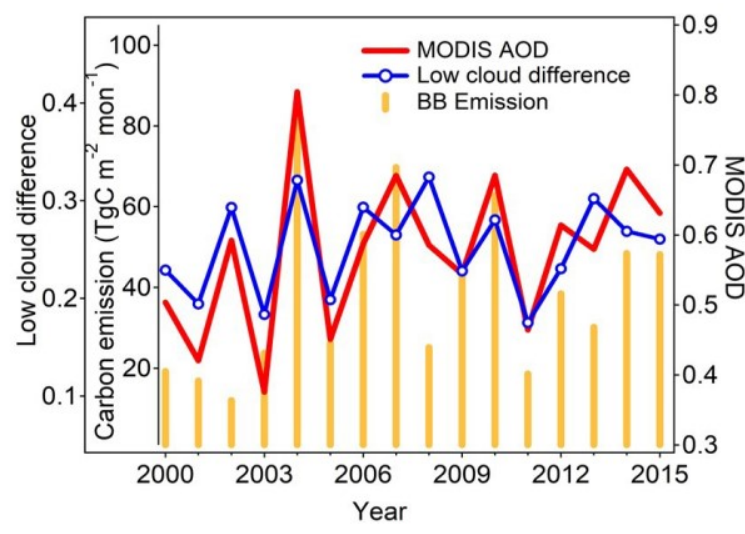

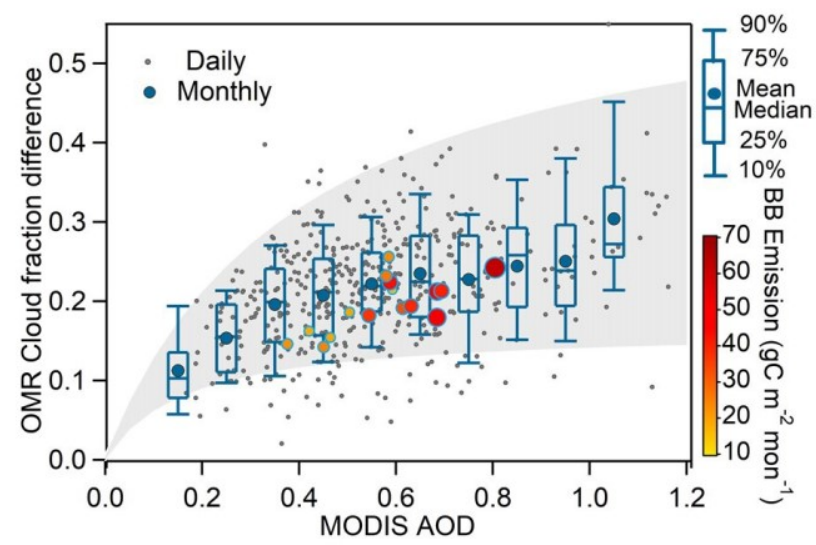

Fig. 1. Observation minus Reanalysis (OMR) difference in cloud fraction and its relationship to aerosol optical depth. OMR differences in cloud fraction together with $925 \mathrm{hPa}$ wind fields in (A) March in Asia and (B) August in Africa, respectively, during 2000-2015. (C) Time series of monthly-averaged OMR difference of low clouds (with MODIS cloud amount as the observation) and MODIS AOD for Asia in March (the region for averaging are denoted in fig. S1A). (D) Low-cloud enhancement as a function of AOD in subtropical southeastern Asia in March during 2000-2015. Note: The gray dots in Figs. 1A and 1B show satellite-detected fire counts. The blue boxes labeled $\mathbf{a}$ and $\mathbf{b}$ in Fig. 1A define regions with the highest OMR values for further analysis in Fig. 2. In Fig. 1D, gray dots show daily regional results and the whiskerbox plot gives the statistics of daily data with different AOD bins. The daytime cloud enhancement between the $10^{\text {th }}$ and $90^{\text {th }}$ percentiles are marked as the gray shading, and monthly results are color-coded with marker size indicating BB emission in the source region. 

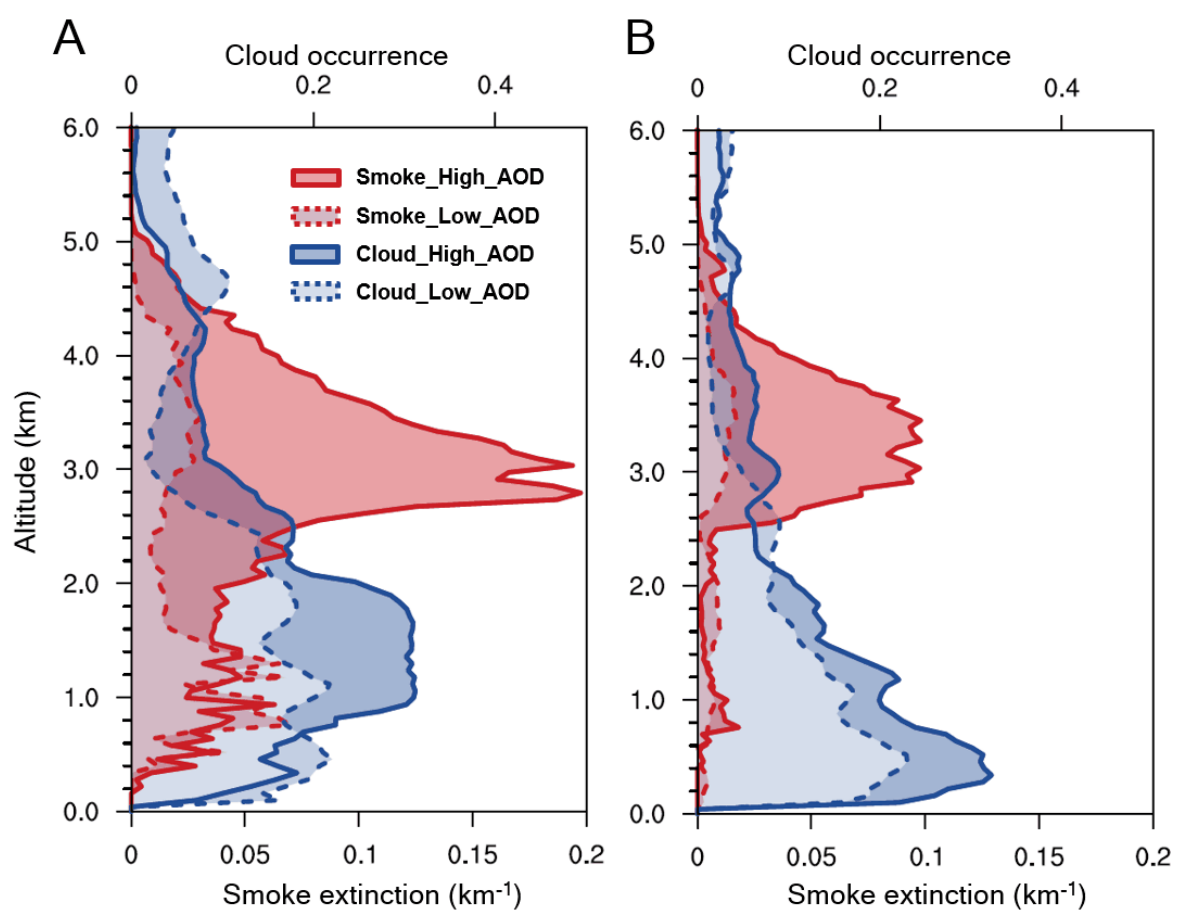

Fig. 2. Relationship between smoke and cloud occurrences measured by the CALIPSO satellite instruments. Averaged vertical profile of Cloud-Aerosol Lidar and Infrared Pathfinder Satellite Observation (CALIPSO) smoke extinction and cloud occurrence in the three years with highest and lowest smoke aloft during 2007-2015 for (A) Baibu Bay (2010, 2012, 2014 as high years compared to 2008, 2009, 2011) and (B) Taiwan Strait (2007, 2010, 2015 as high years compared to 2008, 2012, 2013). Region definitions are given in Fig.1A. The highest and the lowest three years were classified according to the column smoke extinction between 2 and $5 \mathrm{~km}$, excluding years with inconsistent AOD and extremely high smoke aerosol concentrations in the cloud. 

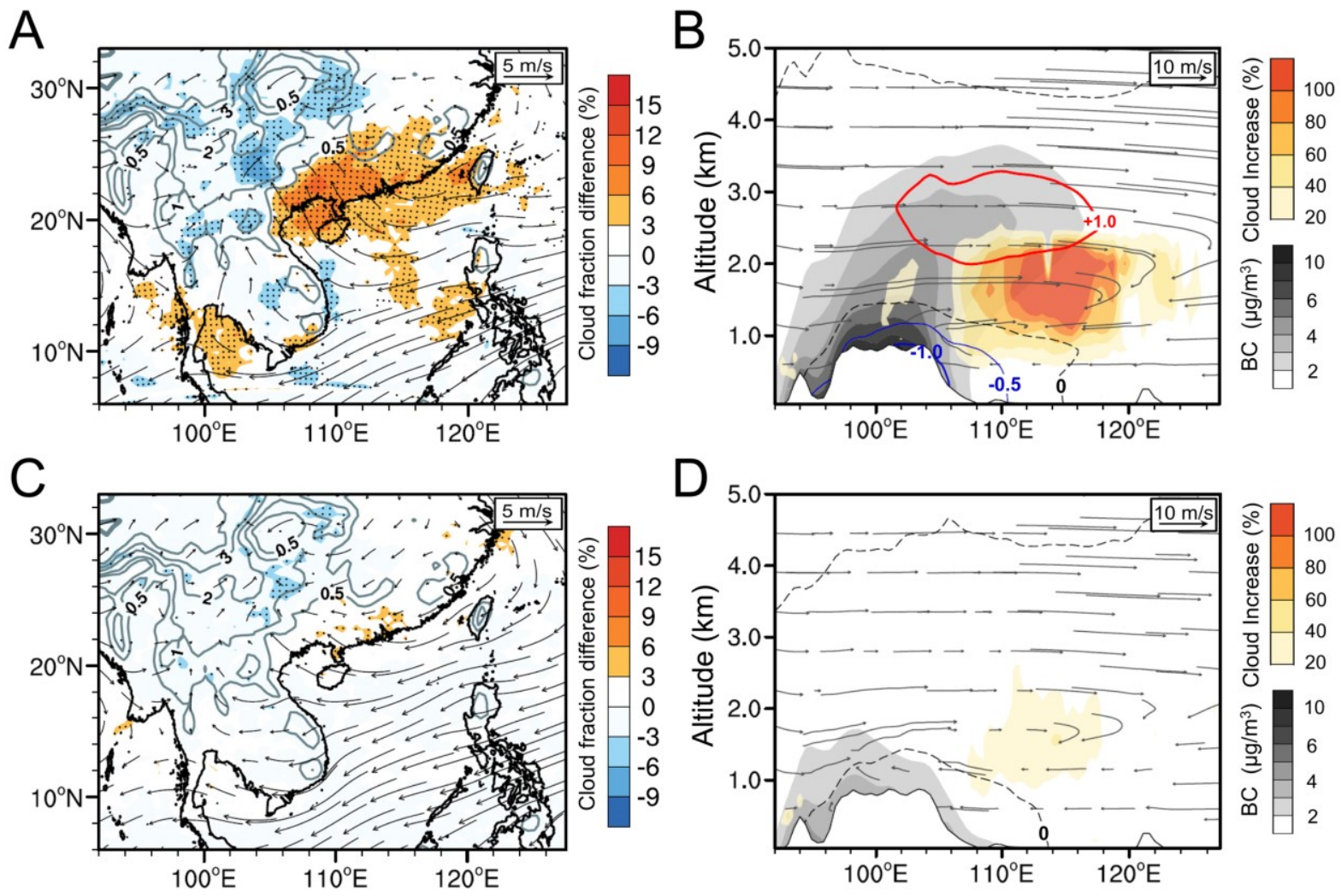

Fig. 3. Synergetic effect of smoke-cloud-PBL feedback coupling with the monsoon circulation in subtropical southeastern Asia elucidated by WRF-Chem simulations. (A) Monthly averaged difference of low cloud fraction plotted with $925 \mathrm{hPa}$ winds in March of high AOD years (2004, 2007, 2010 and 2014). (B) Vertical cross-section of BC concentration, cloud enhancement and air temperature difference along the coastal region $\left(17^{\circ} \mathrm{N}-23^{\circ} \mathrm{N}\right)$ for the runs with BB on/off in March of 2004, 2007, 2010 and 2014. (C) and (D) Same as Figs. 3AB but for low AOD years $(2001,2003,2005,2011)$. Note: The results are calculated from the difference between the experiments EXP_FAR and EXP_exAR. Gray isolines in Figs. 3Aand 3C show topography (Unit: $\mathrm{km})$ and black dots mark the grids passing a T-test. 


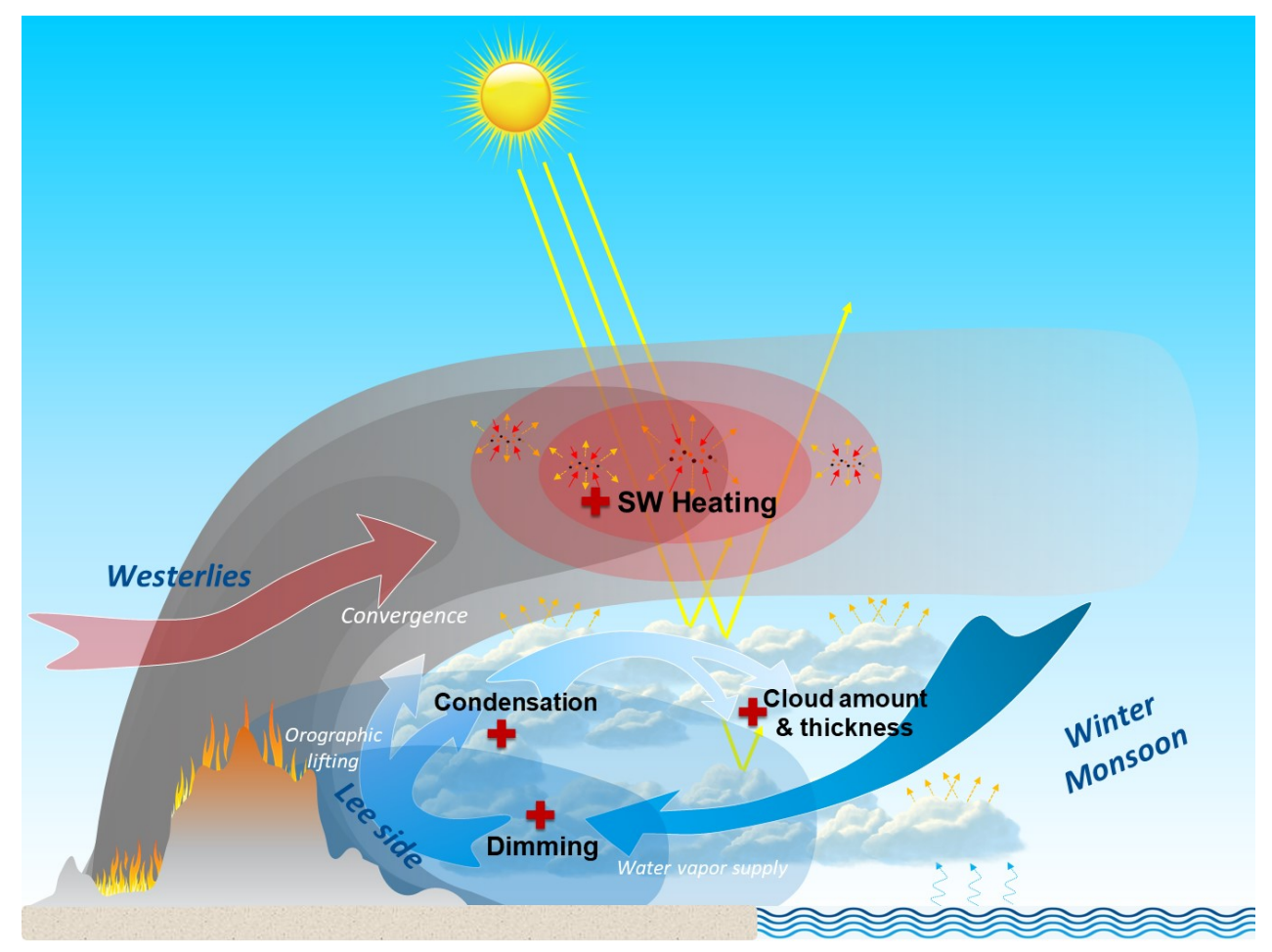

Fig. 4. Mechanism of smoke-cloud-PBL feedback coupling with the monsoon in subtropical southeastern Asia. The shaded gray color indicates the biomass-burning plume. The red color along the plume shows shortwave heating by absorbing aerosols like $\mathrm{BC}$ above the clouds. Shaded blue color on the lee side of the plateau indicates the strong dimming caused by aerosolcloud-PBL interactions over land. 


\section{Supplementary Materials for}

\section{Amplified semi-direct effect of biomass burning aerosols on low cloud formation by Asia monsoon}

K. Ding $\dagger$, X. Huang†, A.J. Ding*, M.H. Wang, H. Su, V.-M. Kerminen, T. Petäjä, Z. M. Tan, Z. L. Wang, D.R. Zhou, J. Sun, H. Liao, H.J. Wang, K. Carslaw, R. Wood, P. Zuidema, D. Rosenfeld, M. Kulmala, C.B. Fu, U.

Pöschl, Y. Cheng*, M. O. Andreae

Correspondence to: dingaj@nju.edu.cn (A.D.), yafang.cheng@mpic.de (Y.C)

$\dagger$ K. Ding and X. Huang contributed equally to this work.

This PDF file includes:

Materials and Methods

Figs. S1 to S18

Tables S1 to S4 


\section{Materials and Methods}

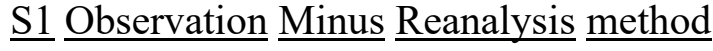

The Observation Minus Reanalysis (OMR) approach, based on the assumption that the difference between observations and models reflects the impact of un-resolved processes, is a wellestablished method in atmospheric science to study anthropogenic impacts on meteorology (1-4). Data assimilation in global reanalysis models usually tends to exclude observations with a bias over a certain threshold (5). It means that these real biases, which result from missing physical or chemical processes in the model, have been mis-considered as observational errors and discarded during the data assimilation procedure for the reanalysis data (1). Therefore, investigation of the difference between observation and reanalysis provides a chance to study specific processes, especially in a certain region. For example, Kalnay et al. (2003) and Zhao et al. (2014) used it to study the impact of urbanization on climate change (2, 4); Ding et al. (2013) and Huang et al. (2018) adopted this method to examine the impact of air pollution on lower tropospheric air temperature for episodes and climatological statistics in the polluted eastern China (1, 6). All these works have demonstrated that the OMR method is well suited to identify the effects from unresolved human impacts on the lower tropospheric air temperature.

In this study, we applied the OMR method in cloud fraction analysis to locate the "hot spots" of typical regions with cloud influenced by biomass burning, i.e. Southeastern Asia and AtlanticAfrica, for further mechanism diagnoses and discussions. By using MODIS satellite retrievals as "observation" and ERA-Interim as "reanalysis", we quantified cloud biases and compared it with aerosols in the two regions. We found that the patterns of OMR cloud bias can be well reproduced by the online-coupled model simulations. Through the detailed analyses of model simulation and observations, it turns out that the dominant mechanism is a synergistic effect of the semi-direct radiative forcing and boundary layer dynamical process coupled with the monsoon circulation over the coastal region, rather than indirect effects of aerosols from biomass burning source or fossil fuel combustion. This newly resolved mechanism is directly related to the impact of light-absorbing aerosols on air temperature (both surface and vertical profile), which has been documented to be well resolved by the OMR method $(1-4,6)$. Thus, our results in this study further demonstrate the great potential of this method for the cloud analysis in regions with changes in cloud properties that are mainly dominated by aerosol-radiation interactions, i.e. with clouds influenced mainly by temperature stratification.

\section{$\underline{\text { S2 }} \underline{\text { Satellite data }}$}

MODIS AOD, cloud and fire detection: The moderate resolution Imaging Spectrometer (MODIS) Satellite retrievals provide monitoring for land, ocean, and atmospheric research (7), 
which were extensively used in numerical simulation, model evaluations and data analysis in this study. The MODIS aerosol product monitors the ambient aerosol over the oceans globally and over a portion of the continents. The Level-3 MODIS atmosphere daily product MOD08, which contains observational information on aerosol optical thickness globally, was utilized to illustrate spatial patterns and temporal variations of aerosol pollution in this work (8). MOD08 also incorporates MODIS cloud observations with a $1 \times 1$ degree grid resolution, such as cloud optical and physical parameters. Here, the spatial distribution of cloud and its properties like top pressure and coverage were used in the data analysis. To determine the locations and time of wild fires, we used the MODIS (Moderate Resolution Imaging Spectroradiometer) Thermal Anomalies/Fire daily L3 Global Product (MOD/MYD14A1), which provides fire identification by examining the brightness temperature relative to neighbouring pixels $(9,10)$.

CALIPSO: The Cloud-Aerosol Lidar and Infrared Pathfinder Satellite Observations (CALIPSO) satellite was launched in 2006 and makes continuous measurements of the Earth's atmosphere thereafter. The primary instrument onboard the CALIPSO is the Cloud-Aerosol Lidar with Orthogonal Polarization (CALIOP), a two-wavelength polarization Lidar. Since 2006, CALIOP has been collecting almost continuously high-resolution $(333 \mathrm{~m}$ in the horizontal and $30 \mathrm{~m}$ in the vertical in low and middle troposphere) profiles of the attenuated backscatter by aerosols and clouds at visible and near-infrared wavelengths along with polarized backscatter in the visible channel. Spatial averaging over different scales is taken to improve signal-to-noise-ratio for reliable aerosol retrieval (11). In this work, we used CALIPSO aerosol and cloud measurements in the Level 3 Aerosol Profile Monthly Product to get vertical distributions of smoke extinction and cloud during the biomass-burning season. Smoke extinction at $532 \mathrm{~nm}$ is directly provided by CALIPSO aerosol product. To get a better idea of the vertical profile of cloud frequency, we calculated cloud occurrence, which is defined as the ratio of samples with cloud detection to all samples, for each grid in these two biomass-burning regions.

OMI AAI: The Dutch-Finnish Ozone Monitoring Instrument (OMI) is a UV/Vis imaging spectrometer that measures the upwelling radiance at the top of the atmosphere from the Earth's atmosphere in three spectral channels between 264 and $504 \mathrm{~nm}$ (12). The Absorbing Aerosol Index (AAI) is a measure of the spectral slope of the atmospheric backscattered radiance in the UV as compared to the spectral slope of a pure molecular atmosphere described by Rayleigh scattering. Positive values of the residue denote the presence of UV absorbing particles. Although the AAI does not represent one single aerosol property but rather depends on several properties, its advantage is that it can detect aerosols over a wide variety of scenes, including bright surfaces and clouds. The AAI is a powerful method for tracking aerosol plumes in satellite measurements, and it has been employed in various studies of the transport of aerosol plumes. In this study we used 
the OMI scientific data products of the AAI to describe the interannual variability of aerosol pollution in the two biomass-burning regions.

$\underline{\mathrm{S} 3} \underline{\text { Observational and }} \underline{\text { reanalysis }} \underline{\text { data }}$

Ground and Radiosonde data: In order to validate the model performance in simulating the meteorological fields like air temperature and cloud cover, several relevant observations were introduced here. Hourly surface meteorological observations, including near-surface air temperature and cloud observations, were obtained from Integrated Surface Hourly (ISH) Data archived at the National Climatic Data Center (NCDC, available at https://www.ncdc.noaa.gov/isd). It is composed of worldwide surface weather observations from over 20,000 globally distributed stations. The Integrated Global Radiosonde Archive (IGRA) contains radiosonde and pilot balloon observations globally, which provides vertical temperature profiles. Both ISH and IGRA data are accessible at the NCAR Research Data Archive (http://rda.ucar.edu/).

ERA-Interim Reanalysis: Air temperature profiles and cloud distribution from the European Centre for Medium-Range Weather Forecasts (ECMWF) Interim Re-Analysis (ERA-Interim) were obtained to compare with the regional simulations and corresponding observations (5). The ERA-Interim data assimilation system used to produce ERA-Interim is based on the 2006 release of the ECMWF's Integrated Forecast System (IFS). ERA-Interim has assimilated multiple measurements through a four-dimensional variational data assimilation system in 12-hourly analysis cycles(13). However, prior state estimates from the forecast model determine how much of the observational information can be retained and lead to a large drop between the total number of available data and the number of data passed to the assimilation. In fact, only less than $50 \%$ of total radiosonde measurements are assimilated in the ERA-Interim dataset (14). Accordingly, disparities between atmospheric radiosonde observations and ERA-Interim reanalysis data could somehow reflect the effects induced by pollution statistically. In our previous study, we have used the difference in air temperature to investigate the impact due to aerosol pollution in North China, which has been proven to characterize reasonably well the modified temperature stratification caused by light-absorbing aerosols (15). Here, a similar method was applied to identify effect of biomass burning aerosols on low cloud formation.

\section{$\underline{\text { S4 Emission inventories }}$}

Emissions from biomass burning: The Global Fire Emissions Database, Version 4.1 (GFED4s) provides monthly burned area and fire carbon emissions all around the globe during the time period from 1997 to 2015. It is based on an updated version of van der Werf et al. (2010) with 
burned area from Giglio et al. (2013) boosted by small fire burned area $(16,17)$. The spatial resolution of the global emission is 0.25 degrees, and the temporal resolution is monthly.

Other emission inventories: Both fire emission and anthropogenic emissions were included for the regional WRF-Chem modeling in the present work. Typical anthropogenic emissions were obtained from the MIX database that can be accessed publicly from the website http:/ www.meicmodel.org/dataset-mix (18). MIX emissions sources were classified into five sectors: power plants, residential combustion, industrial process, on-road mobile sources, and agricultural activities. This database covered most of major air pollutants, such as $\mathrm{SO}_{2}, \mathrm{NO}_{\mathrm{x}}, \mathrm{CO}$, volatile organic compounds (VOCs), $\mathrm{NH}_{3}$, particulate matter (PM), BC, and OC. The biogenic VOCs and NO emissions were calculated online using the Model of Emissions of Gases and Aerosols from Nature (MEGAN) (19). More than 20 biogenic species, including isoprene, monoterpenes (e.g., $\alpha$-pinene and $\beta$-pinene) and sesquiterpenes, were considered and then included in the photochemistry calculation.

\section{$\underline{\text { S5 }}$ WRF-Chem modeling}

The numerical simulations in this study were conducted using WRF-Chem, which is an online-coupled three-dimensional, Eulerian chemical transport model considering complex physical and chemical processes, such as emission and deposition of pollutants, advection and diffusion, gaseous and aqueous chemical transformation, aerosol chemistry and dynamics (20). The model has been widely used to evaluate aerosol-radiation interactions (21). In the present work, WRFChem version 3.6.1 was employed. Key physical parameterization options for the model are listed in Table S1. For the aerosol scheme, the CBMZ (Carbon-Bond Mechanism version Z) photochemical mechanism and MOSAIC (Model for Simulating Aerosol Interactions and Chemistry) aerosol model were applied $(22,23)$. Aerosols were assumed to be spherical particles. The size distribution was divided into four discrete size bins defined by their lower and upper dry particle diameters (0.039-0.156, 0.156-0.625, 0.625-2.5, and 2.5-10.0 $\mu \mathrm{m})$. Aerosols in each size bin were assumed to be internally mixed and their optical properties were computed as a function of wavelength based on Mie theory and volume averaged refractive indices $(24,25)$.

The model domains with a $50 \mathrm{~km} \times 50 \mathrm{~km}$ grid resolution, covers Southeast Asia and Atlantic/Africa. There were 30 vertical layers from the ground level to the top pressure of $50 \mathrm{hPa}$. The simulation was conducted for the entire month of March 2004 and August 2010, the strongest BB and low-cloud enhancement months in the past decade for subtropical Asia and Atlantic-Africa, respectively. Each run covered 48 hours with the first 24 hours as model spin-up time and the last 24-hour results used for the final analysis. The initial and boundary conditions of meteorological fields were updated from the 6-hour NCEP (National Centers for Environmental Prediction) global final analysis (FNL) data with a $1^{\circ} \times 1^{\circ}$ spatial resolution. The initial and boundary conditions of 
chemistry were MOZART-4 results acquired from the National Center for Atmospheric Research (NCAR). The chemical outputs from the preceding run were used as the initial conditions for the next. A similar modeling configuration and settings have been successfully adopted in our previous works and have shown good performance on reproduction of aerosol-radiation interactions (26, 27).

To determine the locations and time of biomass burning and the consequent pollutant emissions, the Quick Fire Emission Dataset (QFED) was introduced to characterize spatiotemporal allocations and emission intensity of biomass burning emissions (28). The QFED biomass burning emissions are calculated using the FRP (top-down) approach and comprise emissions for several species, including carbon monoxide (CO), volatile organic compounds (VOC), carbon dioxide $\left(\mathrm{CO}_{2}\right)$, sulfur dioxide $\left(\mathrm{SO}_{2}\right)$, organic carbon $(\mathrm{OC})$, black carbon $(\mathrm{BC})$ and fine particular matter $\left(\mathrm{PM}_{2.5}\right)$. It was input into the "Characterising Brazilian biomass burning emissions using WRFChem with MOSAIC sectional aerosol" (3BEM) module to derive daily varied emission rates from biomass burning (29).

Six parallel numerical experiments were performed to investigate the impacts of biomassburning plumes on cloud over the South China sea, with the first four and the last two aiming at the effects of aerosol radiative interaction (ARI) and aerosol-cloud interaction (ACI) on clouds, respectively: 1) a regular simulation without any aerosol feedback (EXP_exAR), in which radiation transfer was not influenced by atmospheric aerosols, 2) a simulation with the full aerosol feedback (EXP_FAR), in which optical properties of aerosol were calculated at each time step and then coupled with the radiative transfer model for both short- and long-wave radiation, 3) an experiment with the aerosol feedback but only including anthropogenic emissions (EXP_AAR), in which biomass-burning emissions were subtracted and 4) an experiment that only accounted for the effects of aerosol scattering by eliminating the imaginary part of aerosols (EXP_SAR), 5) a simulation including the effect of ACI from both biomass burning and anthropogenic sources (EXP_FAC), and 6) a simulation only considering the ACI caused by anthropogenic sources (EXP_AAC). For the Atlantic-Africa region, another two parallel numerical experiments were performed to investigate the ARI of smoke on cloud: 1) a simulation without any aerosol feedback (EXP_exAR_AA) and 2) a simulation considering BB aerosol effects on radiation transfer (EXP_FAR_AA). The anthropogenic sources in Africa are ignored because they are much smaller in comparison to biomass burning. The model simulated cloud fraction data need to be converted to two-dimensional so as to compare model data with satellite data. The maximum and random method is used to calculate the overall cloud fraction when there is more than one level of cloud in the vertical, which method assumes that clouds have plane-parallel geometry and internal ho- 
mogeneity. It has maximum overlap between clouds in adjacent levels and random overlap between groups of clouds separated by one or more clear layers. This method is consistent with a statistical analysis of observed cloud distributions and is widely used $(30,31)$.

\section{$\underline{\text { S6 }}$ Lagrangian Modeling}

The transport and dispersion simulations were made using a Lagrangian dispersion model, the Hybrid Single-Particle Lagrangian Integrated Trajectory (HYSPLIT) model developed in the Air Resource Laboratory of the National Oceanic and Atmospheric Administration (Stein et al., 2016). The model calculates the position of particles by mean wind and a turbulent transport component after they are released at the source point for forward simulation or receptor for backward run. In this work, the LPDM simulations followed the method developed by Ding et al. (2013). Briefly, the model was used to conduct hourly forward or backward particle dispersion simulations. In each simulation, particles were released at the site and tracked backward in time for a 7-day period. The hourly position of each particle was calculated using a 3-D particle, i.e. horizontal and vertical, method. The air concentrations were calculated according to the particle number distribution. We calculated the air concentration at a specific layer (for example $3 \mathrm{~km}$ altitude or $100 \mathrm{~m}$ altitude), which represents the distribution of the surface probability or residence time of the simulated air mass. We used the WRF-Chem simulated meteorological data to run the LPDM model. 
A
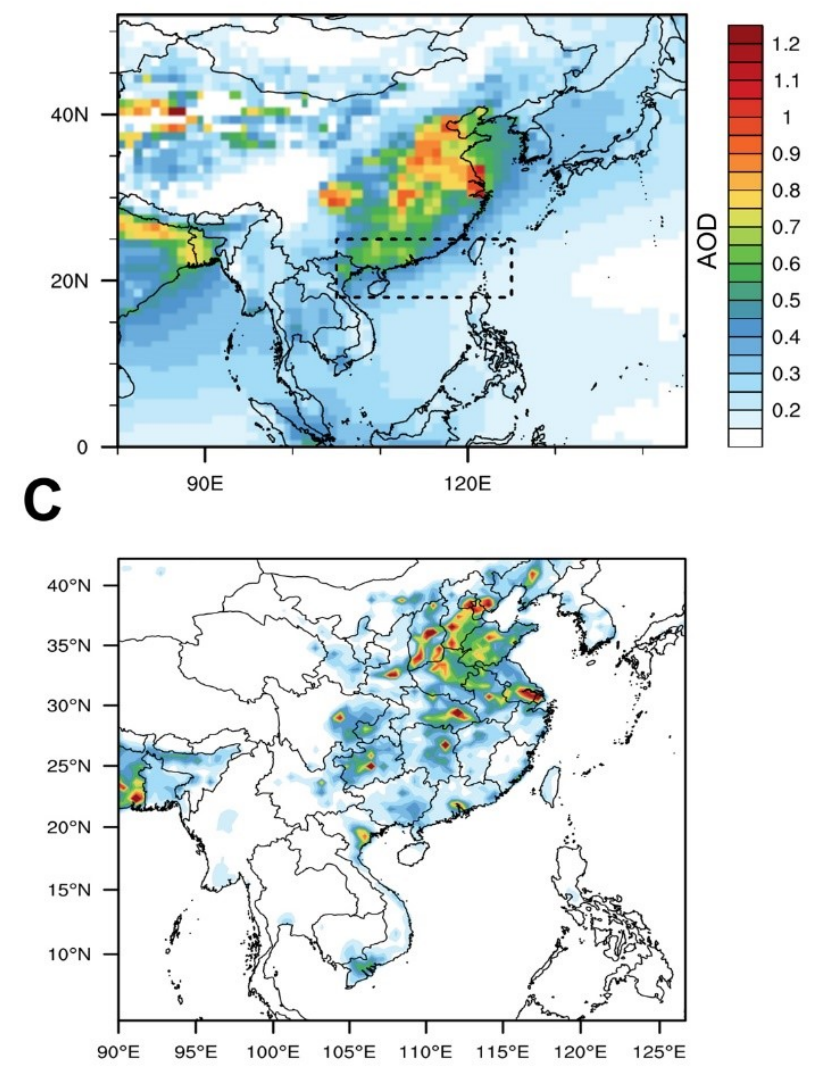

B
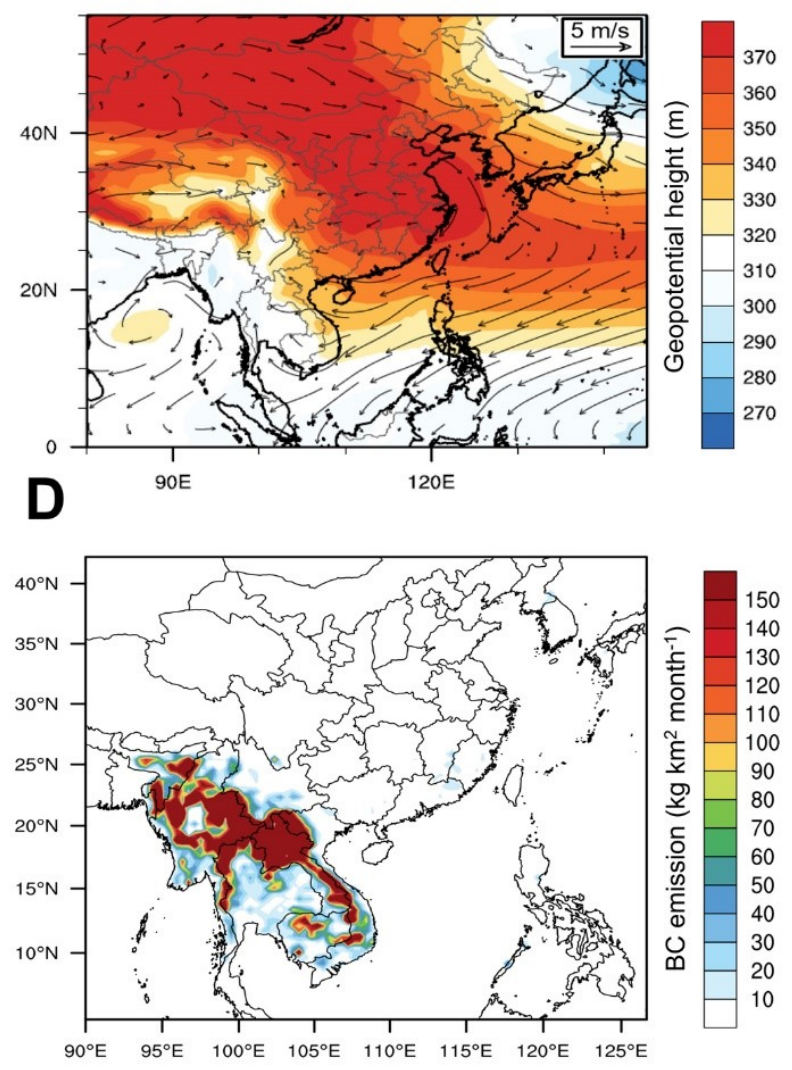

Fig. S1 Distribution of MODIS AOD and BC emissions in East Asia. (A) 2000-2015 averaged MODIS AOD for non-spring months (all months except March and April). (B) 2000-2015 averaged geopotential height and wind field at $975 \mathrm{hPa}$. BC emission intensities from (C) anthropogenic activities and (D) biomass burning in March. Anthropogenic sources derived from MIX emission inventory, and biomass burning sources were calculated online by the 3BEM module embedded in the WRF-Chem model. Note: the dashed box in fig.S1A shows the region where times series of monthly averaged OMR difference of low clouds with AOD are made (fig. 1C). 


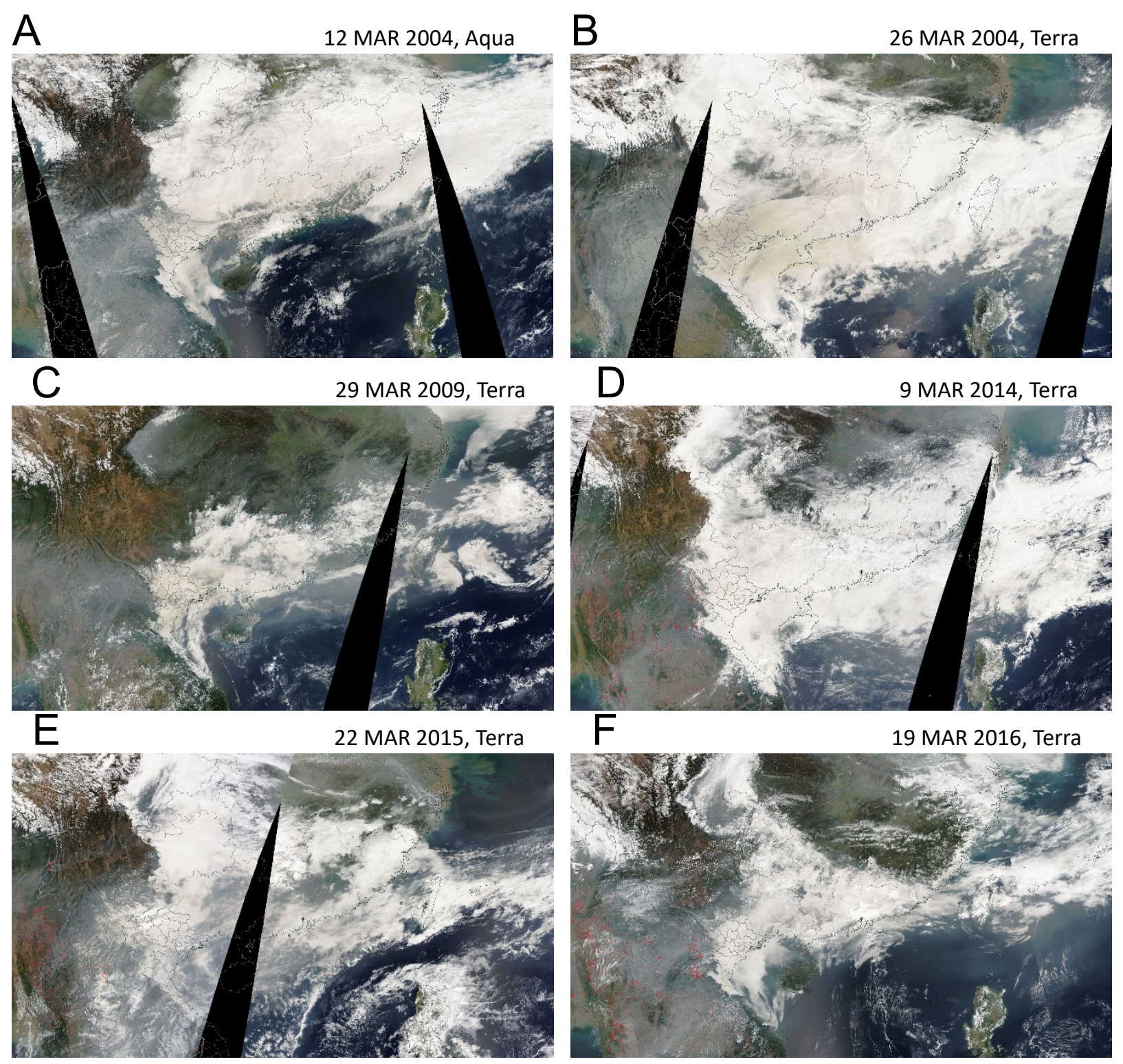

Fig. S2. Satellite images showing low cloud cases in southeastern Asia in BB seasons. MODIS true color corrected reflectance images on (A) 12 March 2004, (B) 26 March 2004, (C) 29 March 2009, (D) 9 March 2014, (E) 22 March 2015, and (F) 19 March 2016. (Source: NASA WORLDVIEW https://worldview.earthdata.nasa.gov/). 


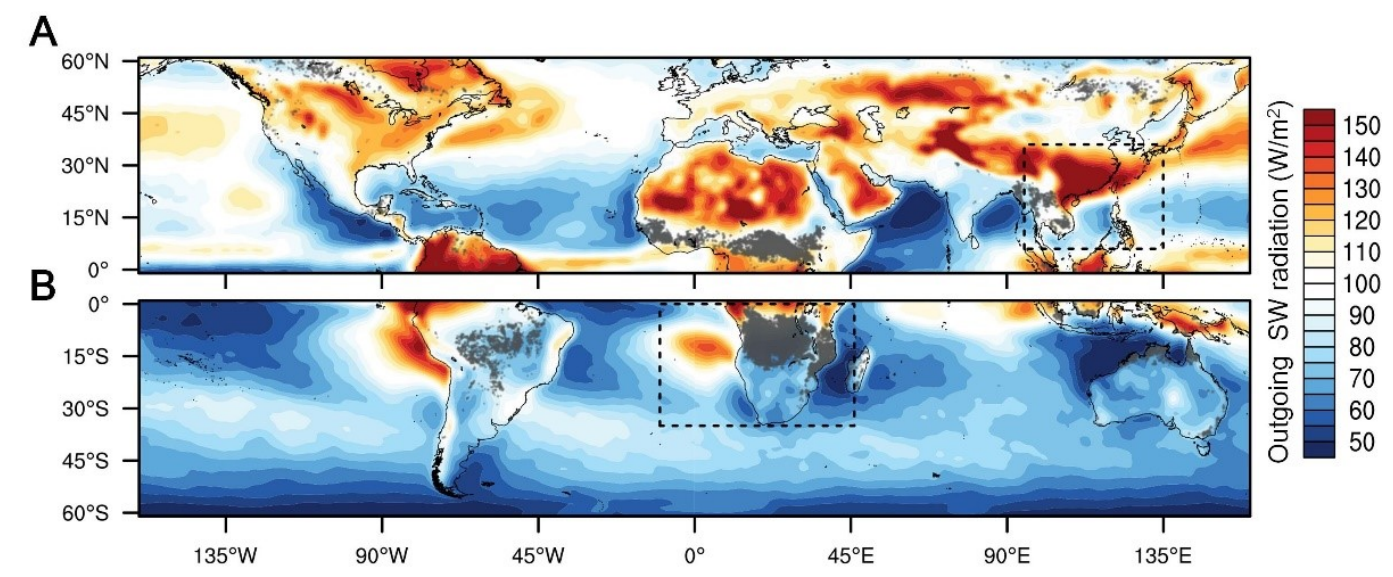

Fig. S3. Outgoing shortwave radiation and biomass burning activities. Distribution of outgoing SW radiation and biomass burning (A) in North Hemisphere in March and (B) in South Hemisphere in August during 2000-2015. Note that biomass burning activities are shown as grey dots based on the MODIS burned area product (MOD/MYD14A1). 


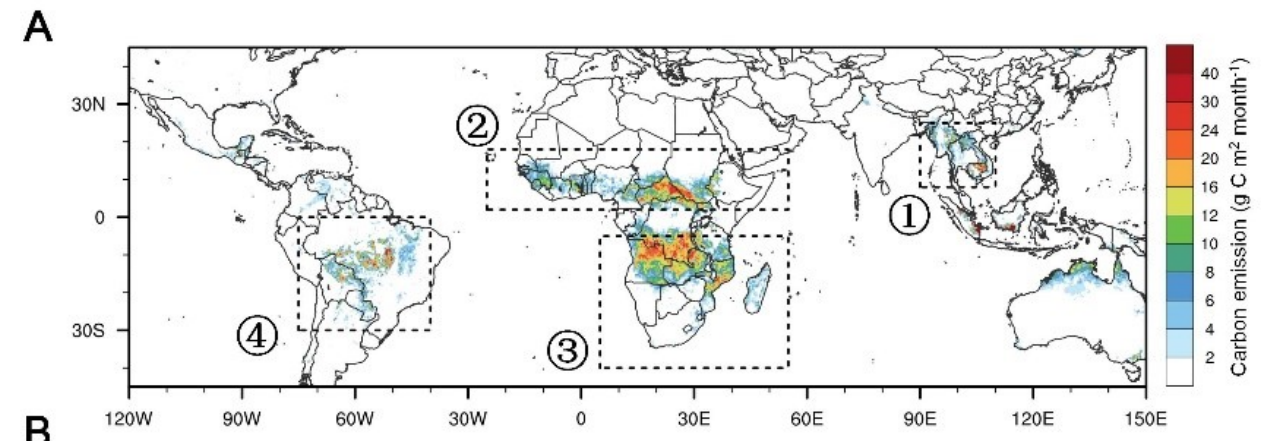

B

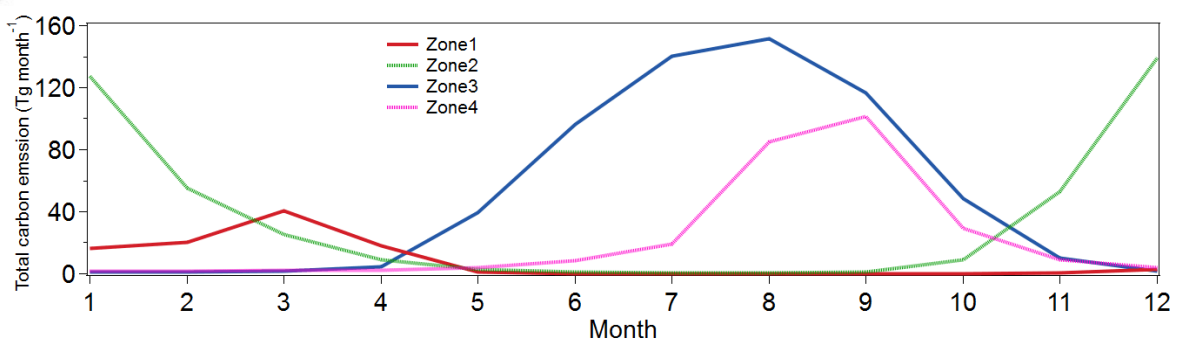

Fig. S4. Biomass burning carbon emission and its seasonal patterns in main $B B$ regions in the world. (A) Global distribution of annual averaged carbon emission from biomass burning, (B) Monthly variation of carbon emission from four typical biomass burning regions: Southeast Asia, North Africa, South Africa and Amazon. 
A

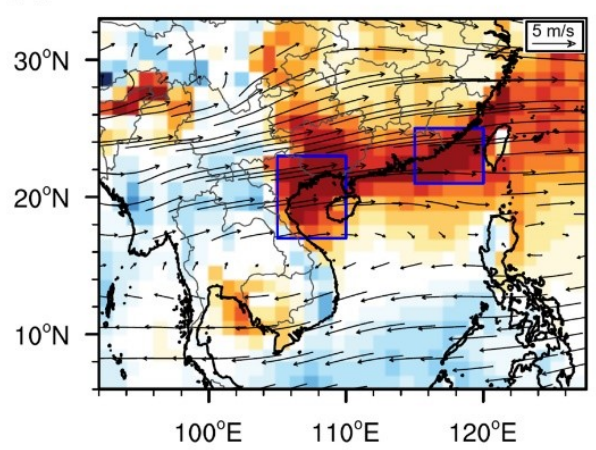

C

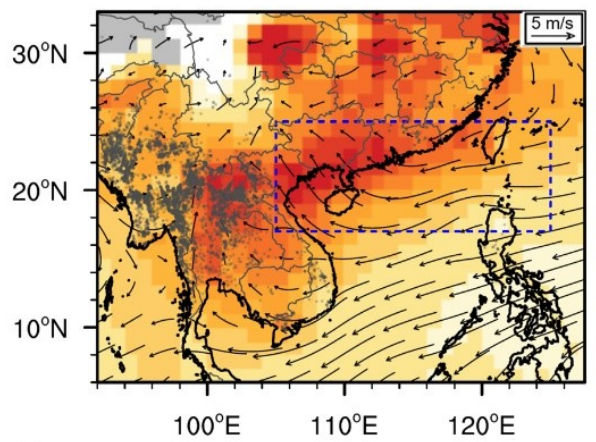

E

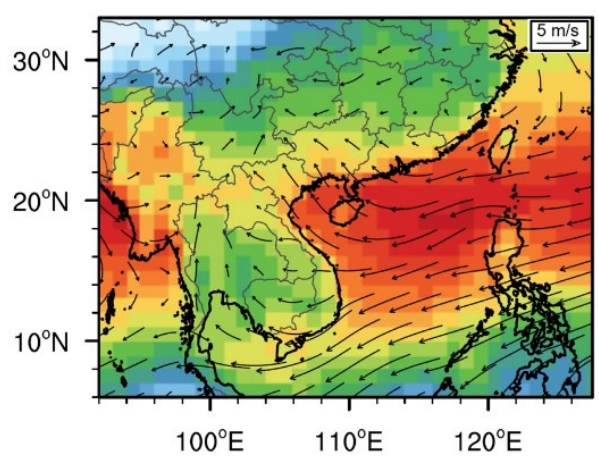

B

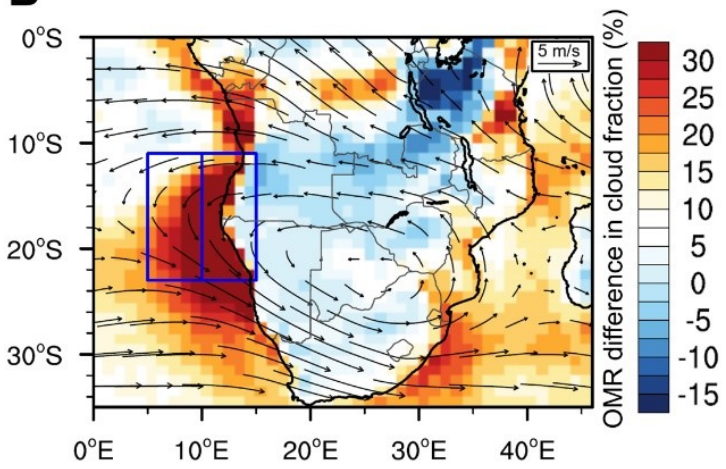

D

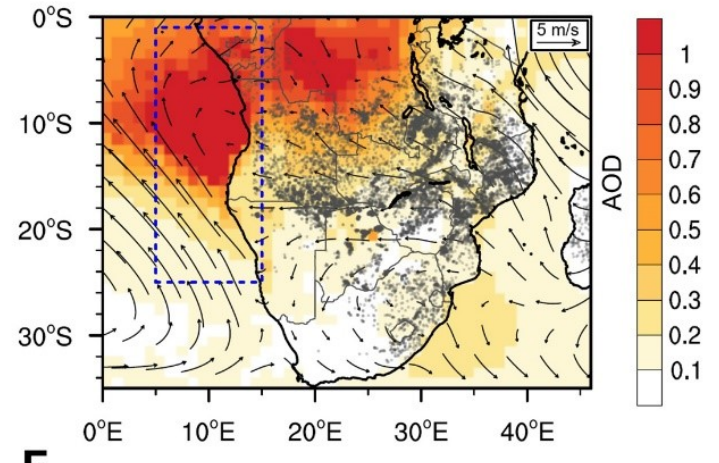

$\mathbf{F}$

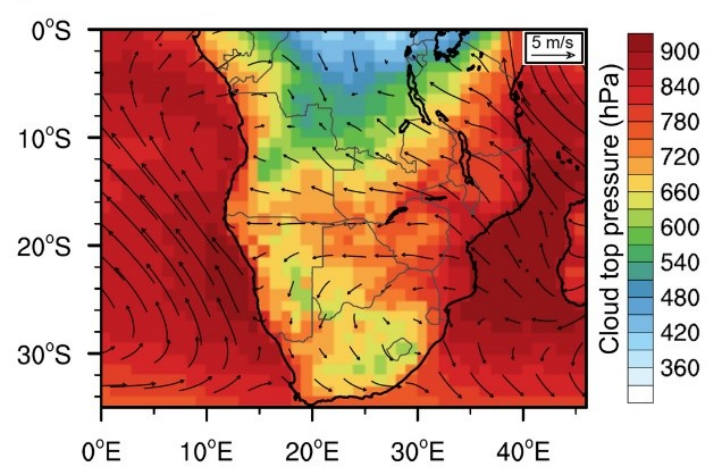

Fig. S5. Distribution of the OMR difference in cloud fraction and the cloud top pressure with region definition. Observation minus Reanalysis (OMR) differences in cloud fraction overlaid by 700-hPa wind (A) in March in Asia and (B) in August in Africa, respectively, during 2000-2015. Averaged AOD overlaid by 925-hPa wind during 2000-2015 (C) in March in Asia and (D) in August in Africa, respectively. (E-F) Cloud top pressure corresponding to Fig. S5A and S5B. Note: Blue boxes in figs. S5A and S5B mark the geographical regions given in Fig. 2, A and B, and fig. S10, A and B. Dashed lines in figs. S5C and S5D define the downwind BB region for Asia and Atlantic-Africa (Fig. 1C, figs. S7). 
A
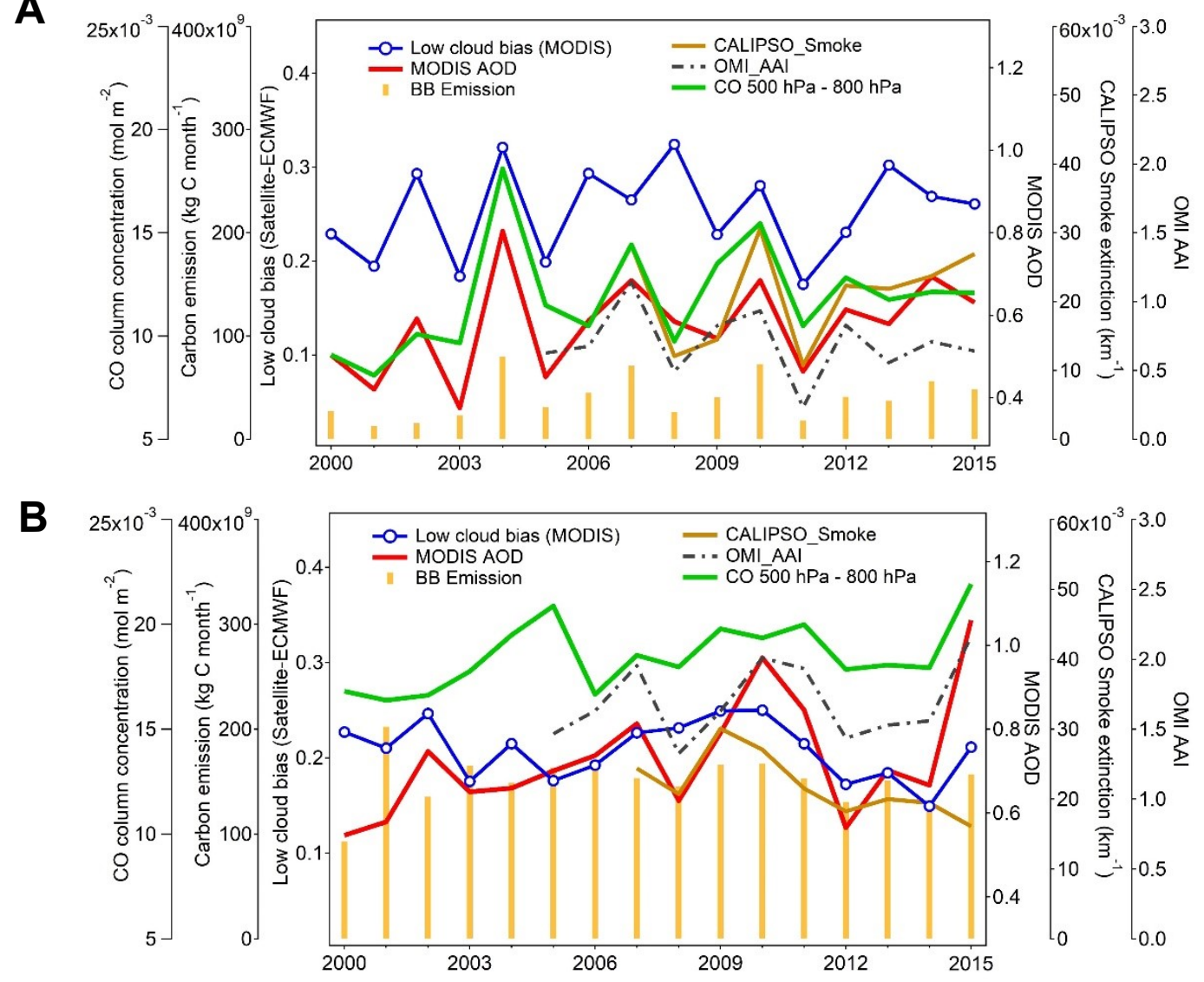

Fig. S6. Inter-annual variations of aerosols and low cloud enhancements in Asia and Africa. Time series of monthly averaged OMR difference of low clouds and various aerosol indices (MODIS AOD, OMI absorption aerosol index (AAI) and CALPSO column smoke extinction) and column CO between 500-800 hPa in the Modern-Era Retrospective analysis for Research and Applications version 2 (MERRA-2) reanalysis for (A) Asia in March and (B) Africa in August during 2000-2015. All data except BB emissions are averaged for low-cloud enhancement regions given in fig. S1A and fig. S5D. (Note: Correlation coefficients between low cloud bias and AOD are 0.78 and 0.37 in Asia and Africa, respectively). 


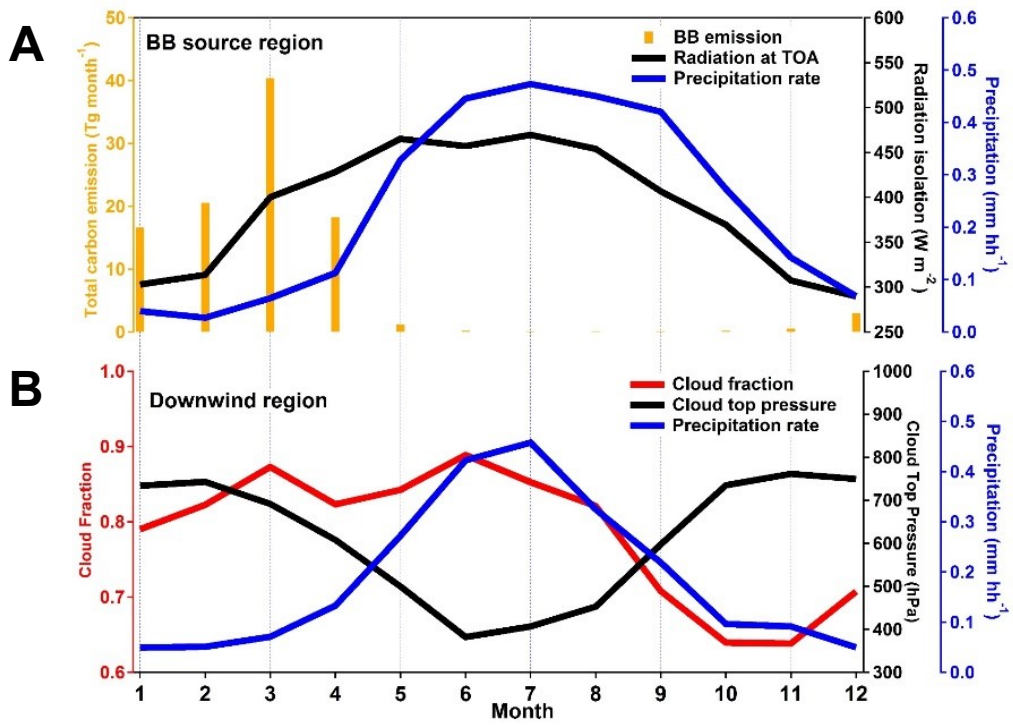

Fig. S7. Seasonal variations of cloud, radiation and precipitation and BB emission in the source and downwind regions. Averaged seasonal profiles of (A) $\mathrm{BB}$ emission, radiation at the top of atmosphere and precipitation rate in $\mathrm{BB}$ source regions of Southeast Asia and (B) cloud fraction, cloud top pressure and precipitation rate at Nanning station downwind the BB source region during 2000-2015. Source: GFED4 for BB emission, TRMM 3B43 for precipitation and MODIS MOD08 for cloud. 
A
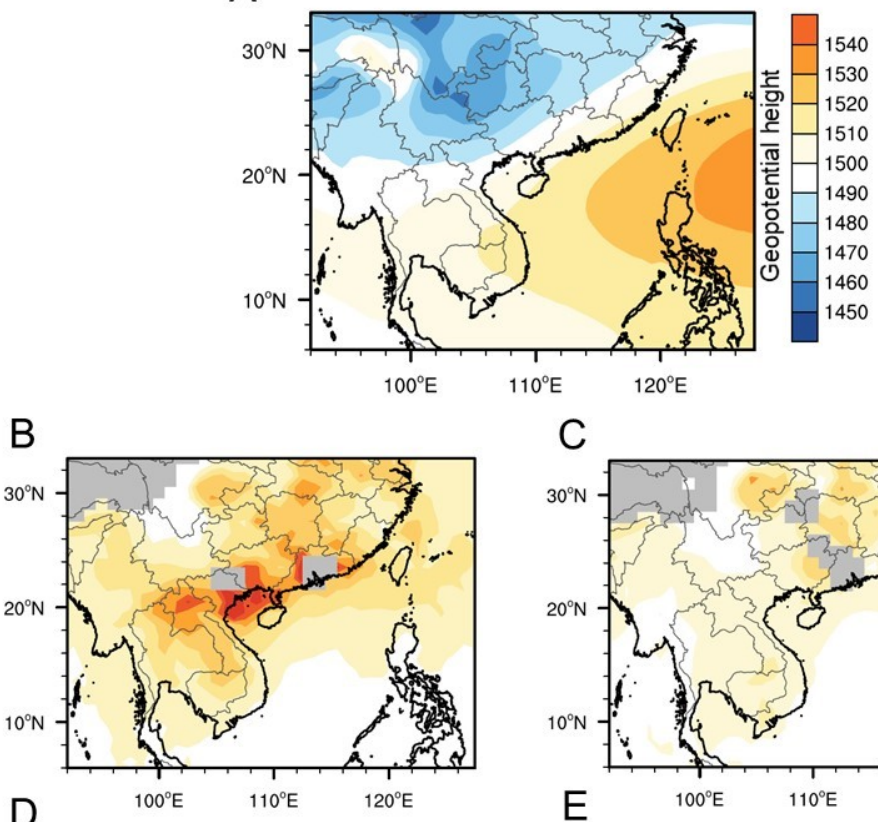

C
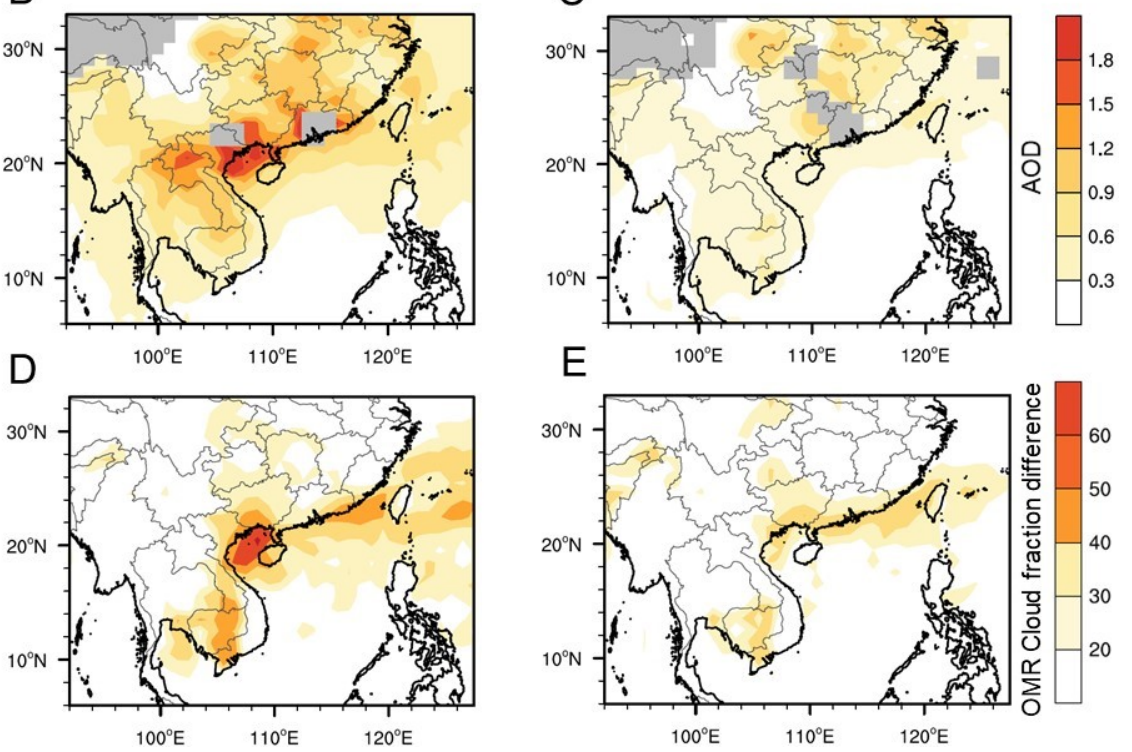

Fig. S8. AOD and OMR difference in cloud fraction under specific typical weather pattern of low clouds in subtropical southern Asia. (A) Averaged $850 \mathrm{hPa}$ geopotential height for 80 selected high low-cloud days with same weather pattern identified using Kirchhofer weather typing approach, which considers correlation of geopotential heights at $850 \mathrm{hPa}$ between different days (32). Averaged AOD distributions for (B) the highest $25 \%$ and (C) the lowest 25\% AOD days, respectively. Averaged OMR cloud fraction bias for (D) the highest $25 \%$ and (E) the lowest $25 \%$ AOD days. 
A

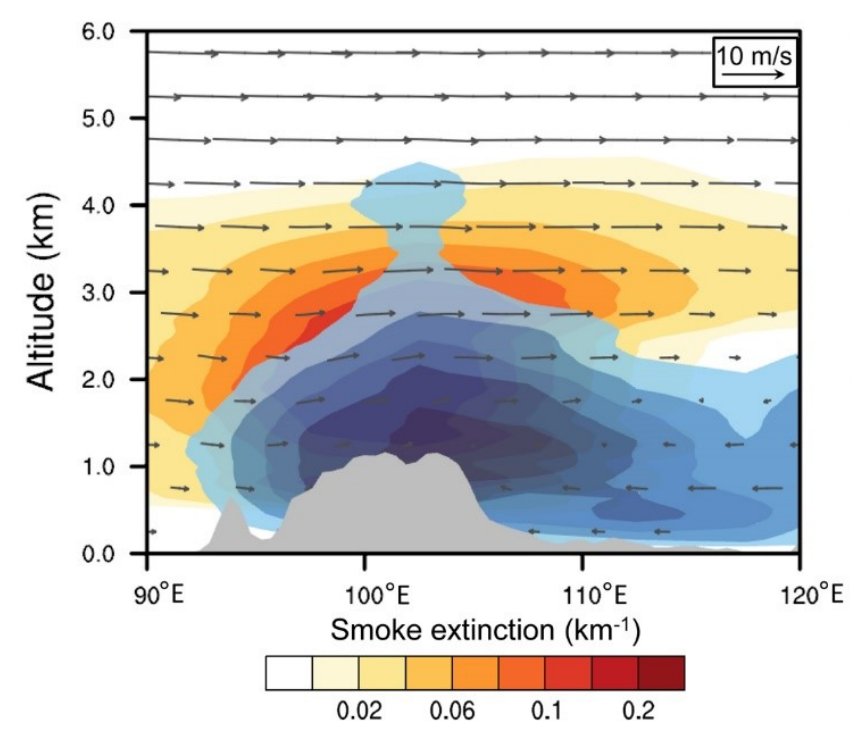

B

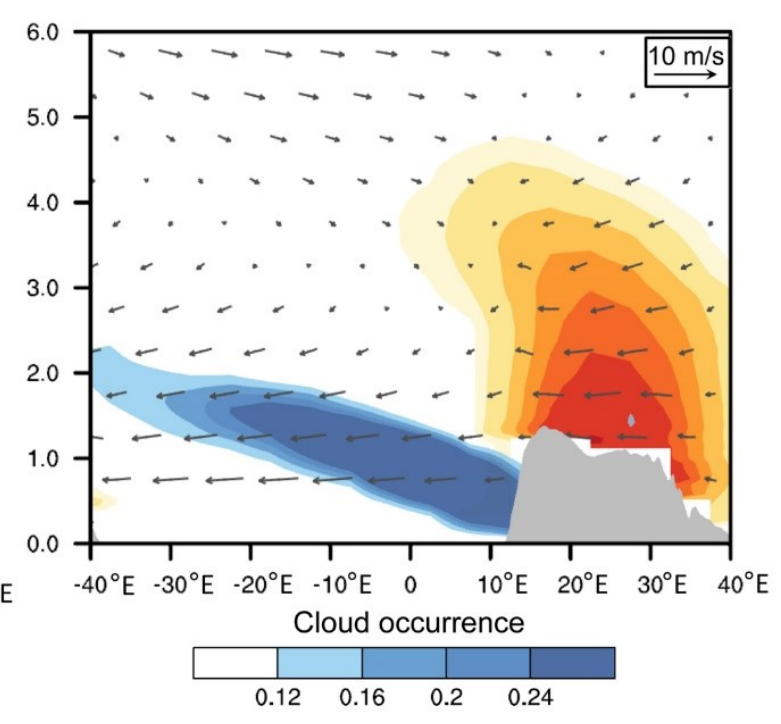

Fig. S9. CALIPSO vertical distribution of smoke extinction and cloud occurrence. Averaged vertical cross-section of smoke extinction and cloud occurrence in (A) subtropical eastern Asia $\left(17^{\circ} \mathrm{N}-23^{\circ} \mathrm{N}\right)$ in March, and (B) Atlantic-Africa region $\left(11^{\circ} \mathrm{S}-23^{\circ} \mathrm{S}\right)$ in August during $2007-$ 2015. 


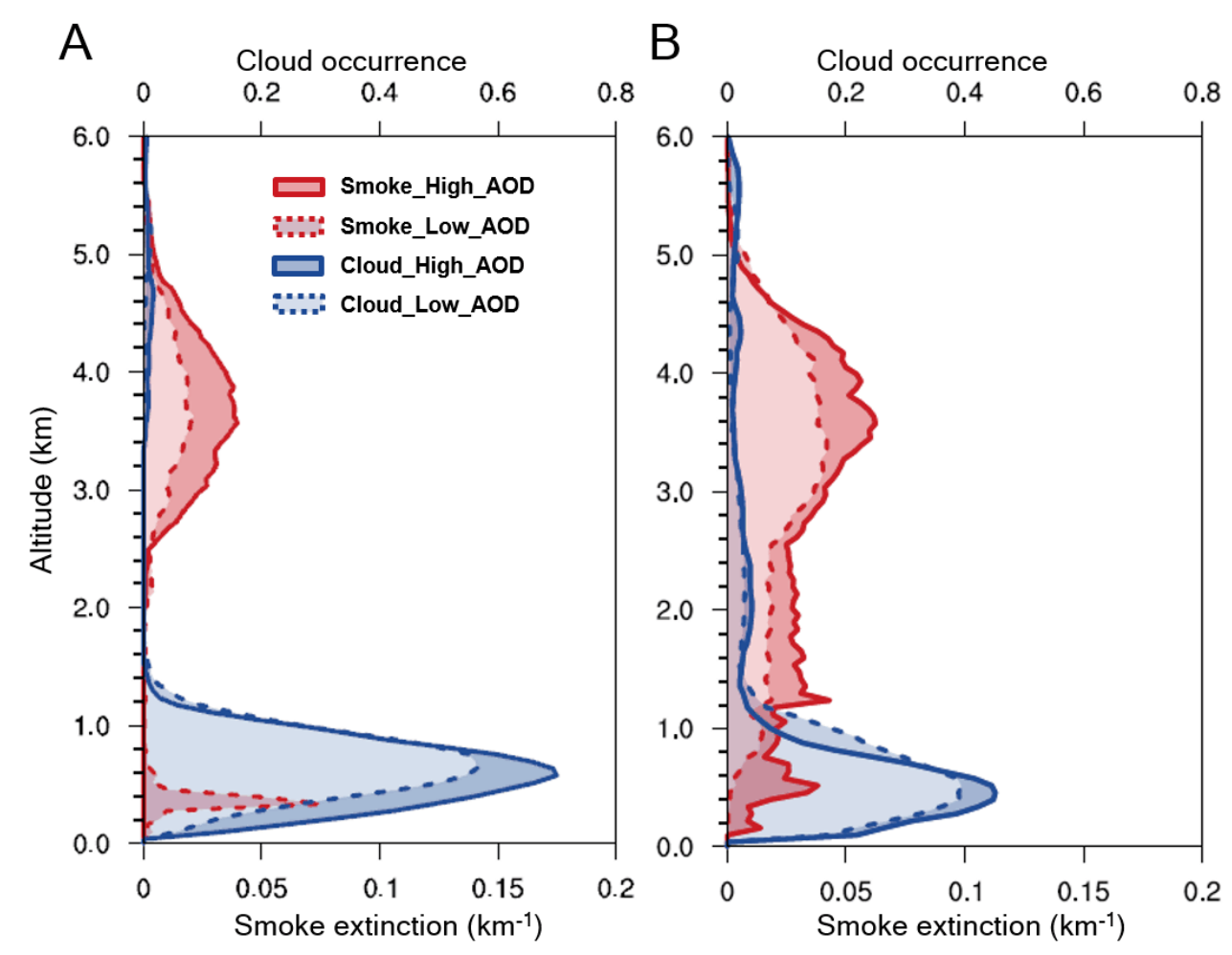

Fig. S10. CALIPSO vertical distribution of smoke extinction and cloud occurrence in the

Africa-Atlantic region. Averaged vertical profile of smoke extinction and cloud occurrence in the three highest and lowest upper-level smoke plume years during 2007-2015 for (A) Atlantic Ocean (2007, 2008, 2009 as high year compared with 2012, 2013, 2014), and (B) coastal west Central Africa in the south $(2010,2011,2014$ vs. 2009, 2012, 2013), respectively. Region definitions are given in fig.S5B. The highest and lowest three years were classified according to the column smoke extinction between 2-5 km, excluding years with inconsistent AOD and extremely high smoke aerosols in the cloud. 
A

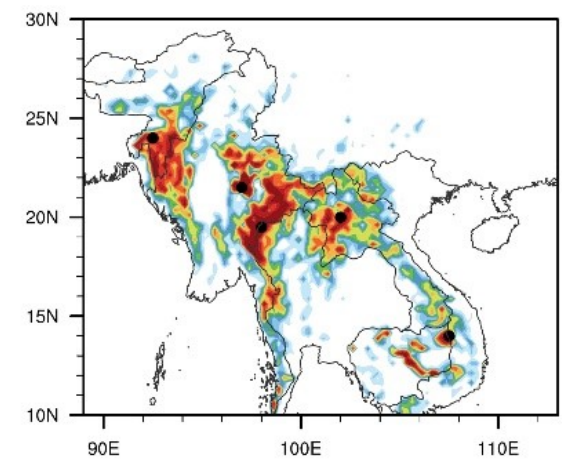

B

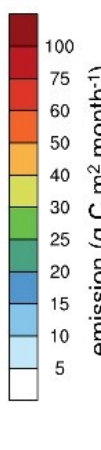

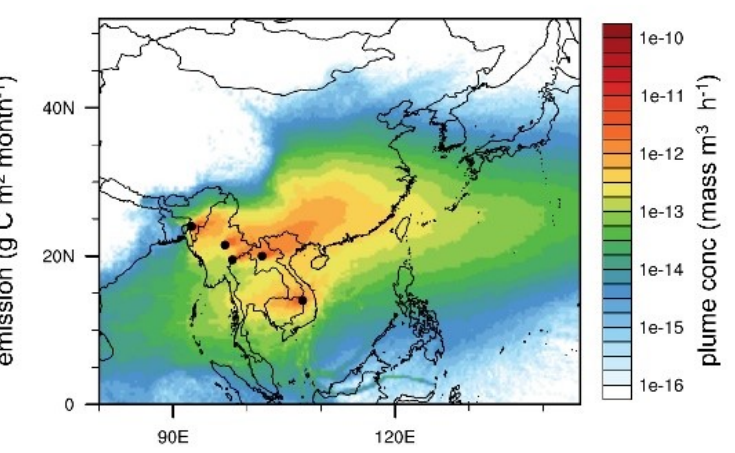

Fig.S11 Lagrangian dispersion modeling for main BB regions in South East Asia. (A) Averaged carbon emission from BB in March (Data from GFED4 emission inventory). (B) Averaged Lagrangian forward dispersion plume at $3 \mathrm{~km}$ altitude from 5 main BB burning regions marked as black dots (Modeling methods are given in SM). 

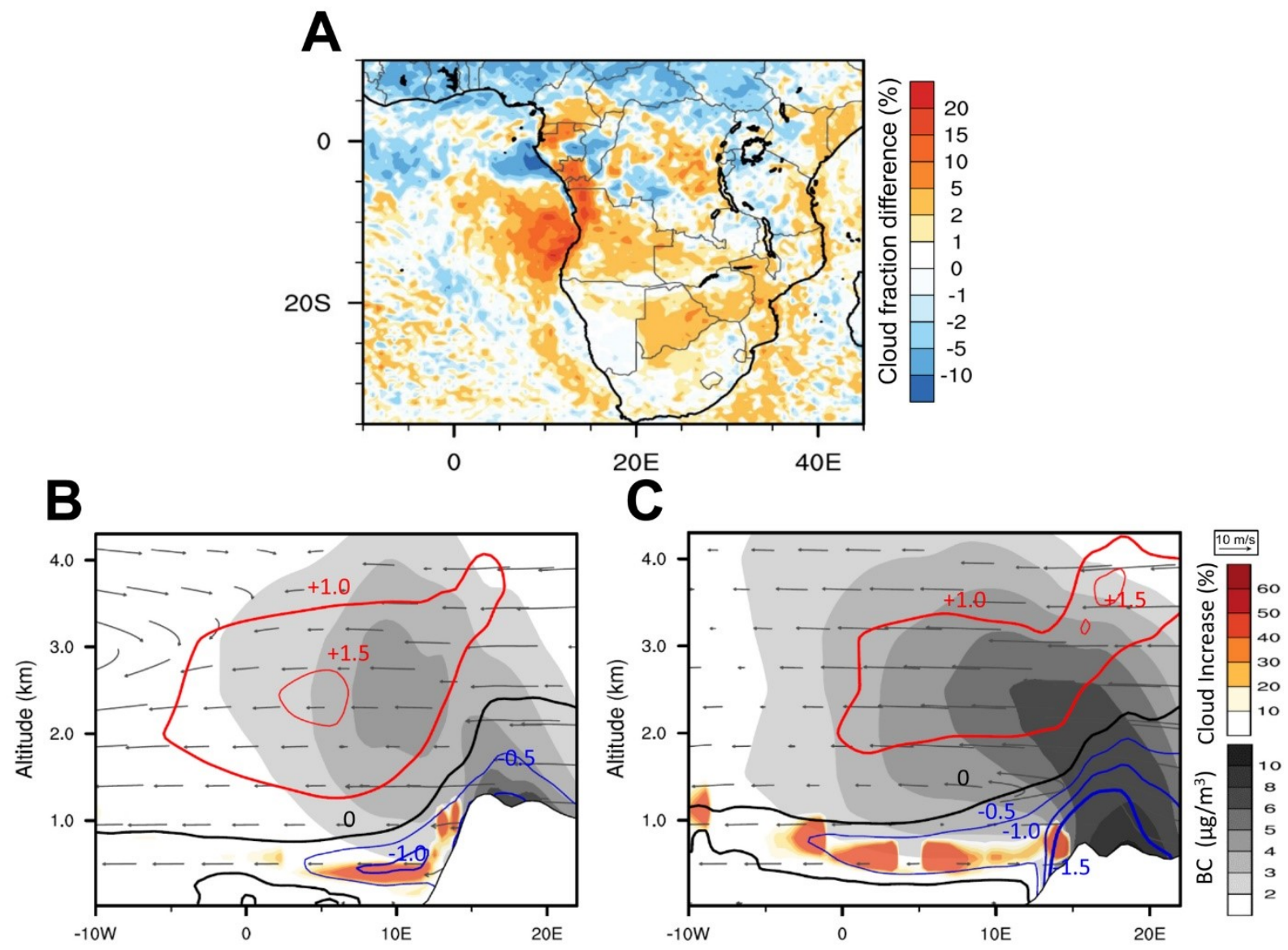

Fig. S12. Biomass burning induced aerosol, clouds and air temperature changes in central Africa. (A) Monthly averaged difference of low cloud fraction for WRF-Chem simulations with fire on/off in Africa in August 2010. Averaged vertical cross-section of BC plumes, relative increase of cloud water and air temperature change by aerosol-cloud feedback along the belts of smoke-induced low cloud enhancement between latitudes of (B) $8^{\circ} \mathrm{S}-18^{\circ} \mathrm{S}$ and (C) $4^{\circ} \mathrm{S}-8^{\circ} \mathrm{S}$ in Africa in August 2010. Note: Results are from the difference between the experiments EXP_FAR_AA and EXP_exAR_AA (Table S4) and BC concentrations are from EXP_FAR_AA. 
A

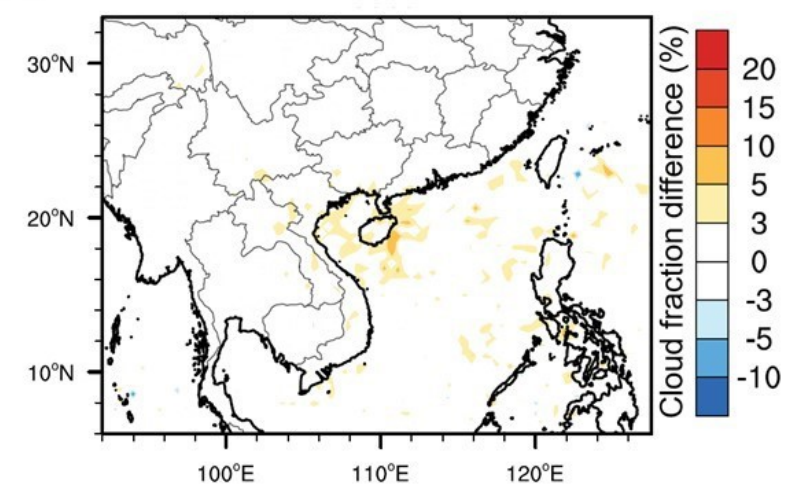

C

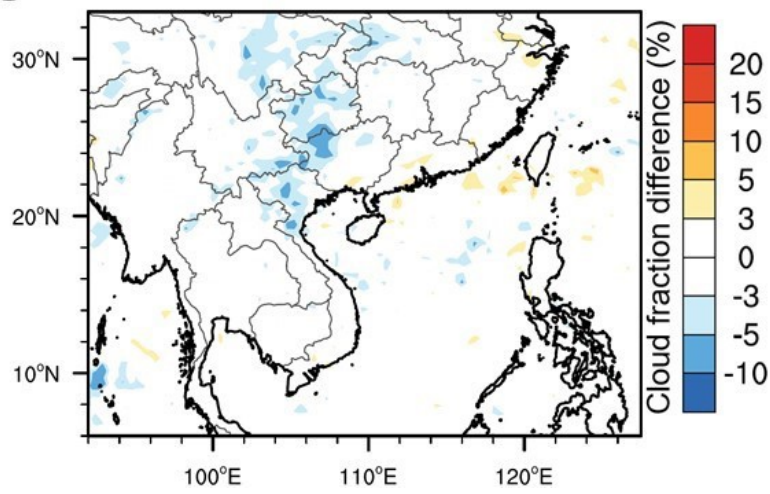

$B$

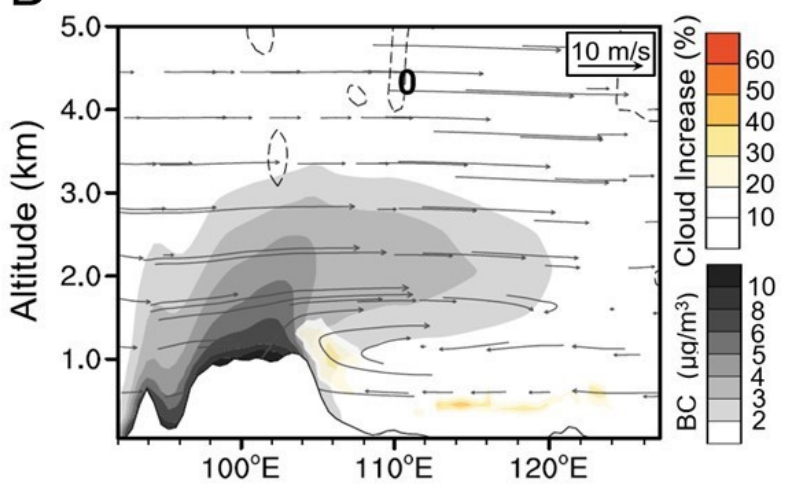

D

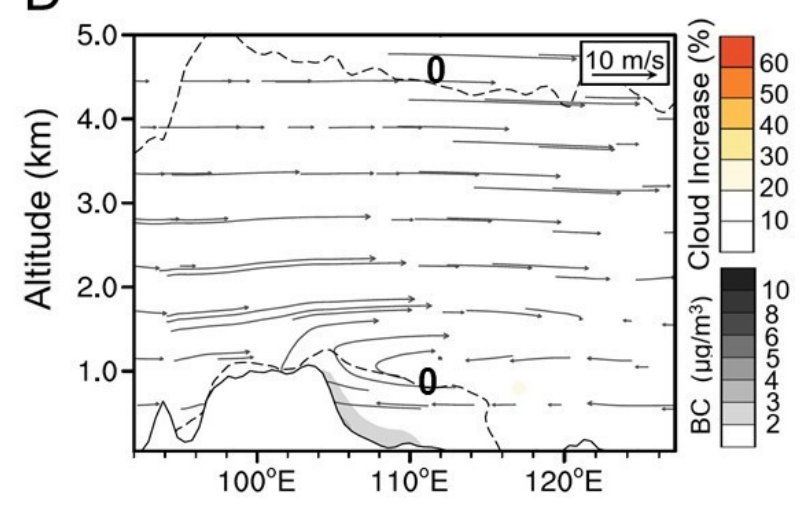

Fig. S13. Roles of different emission sources and interaction processes on cloud fraction in Southeastern Asia. (A) Monthly averaged difference of low-cloud fraction (EXP_FAC EXP_AAC) contributed by aerosol-cloud interaction from biomass burning in Southeast Asia in March 2004. (B) Vertical distribution of BC and cloud enhancement along the coastal region $\left(17^{\circ} \mathrm{N}-23^{\circ} \mathrm{N}\right)$ corresponding to A. (C) same as fig. S13A but for aerosol-radiation interaction from fossil fuel combustion sources (EXP_AAR - EXP_exAR). (D) same as fig. S13B but corresponding to fig. S13C. 

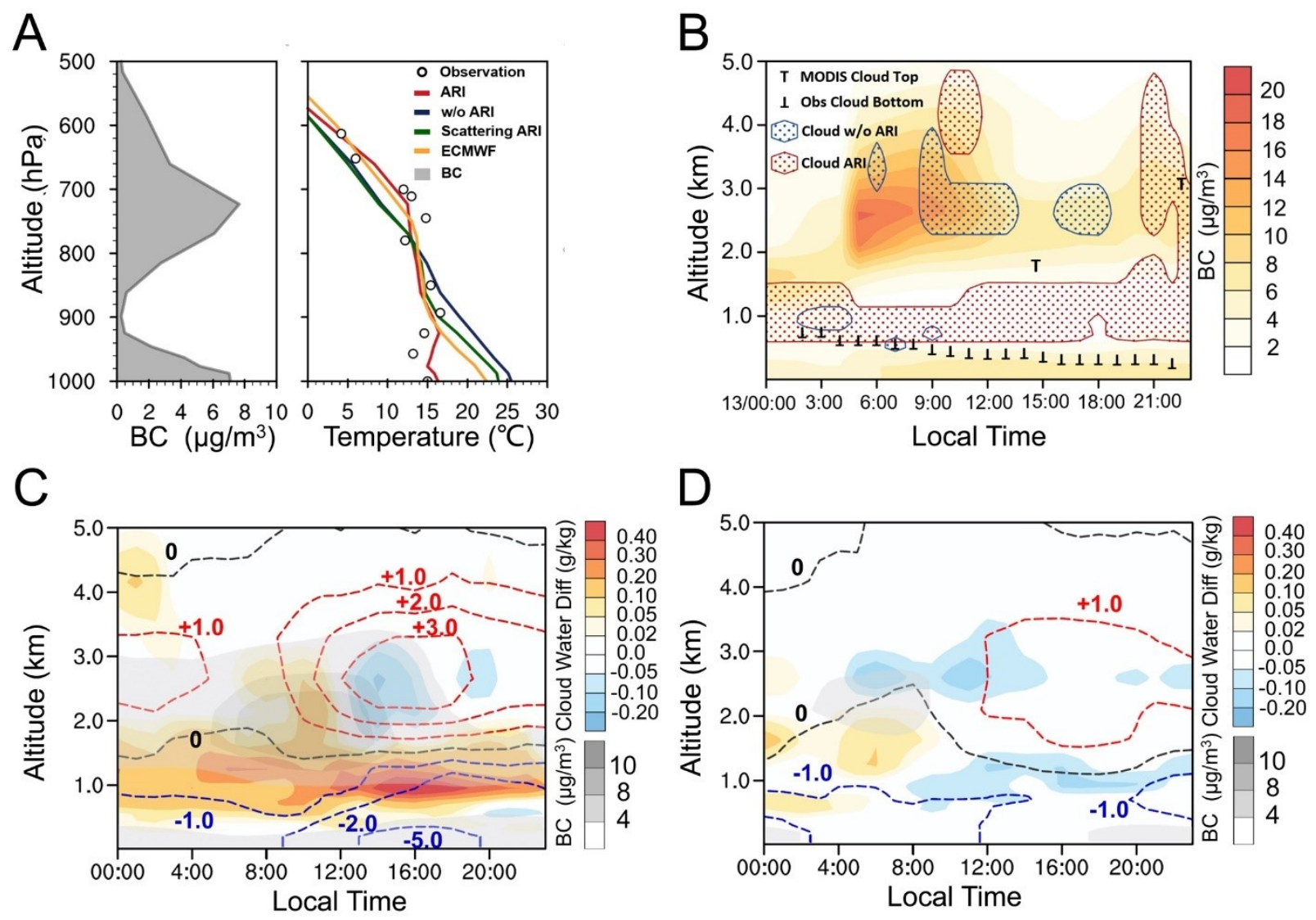

Fig. S14. Vertical structure and diurnal evolution of BC, air temperature, and clouds for typical episodes elucidated by WRF-Chem simulations. (A) Vertical distribution of BC and air temperature in different modeling scenarios over Nanning on 13 March 2004. Note that Aerosol Radiation Interaction (ARI), w/o ARI, Scattering ARI and ECMWF indicate simulations with/without aerosol feedback, only accounting for feedback due to scattering aerosol, and the ECMWF reanalysis, respectively. (B) Diurnal cycle of cloud distributions from the runs with ARI on/off on 13 March 2004, compared with satellite- and ground-based observations. Diurnal cycle of averaged cloud difference and BC concentration for the (C) 8 highest and (D) 8 lowest aerosol-PBL feedback days in Nanning during March 2004. The dashed lines represent the air temperature difference with/without aerosol feedback (Red for heating and blue for dimming), and the aerosol-PBL feedback days were classified using the OMR difference in surface air temperature at Nanning. 
A

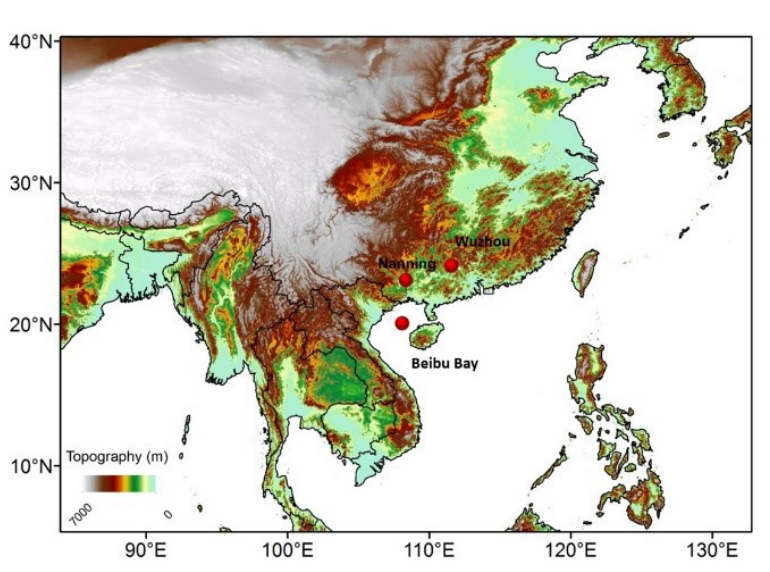

C

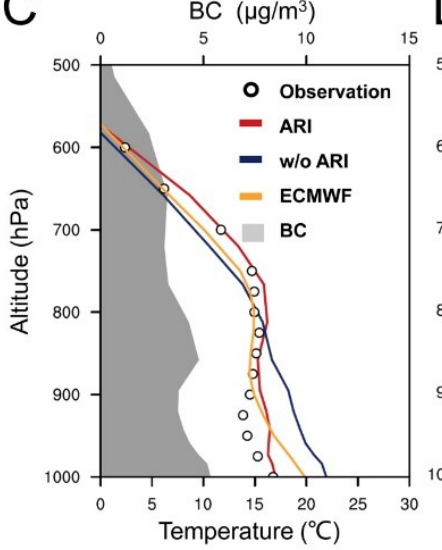

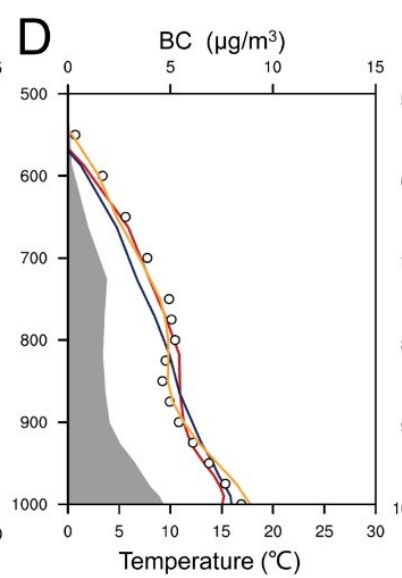

B
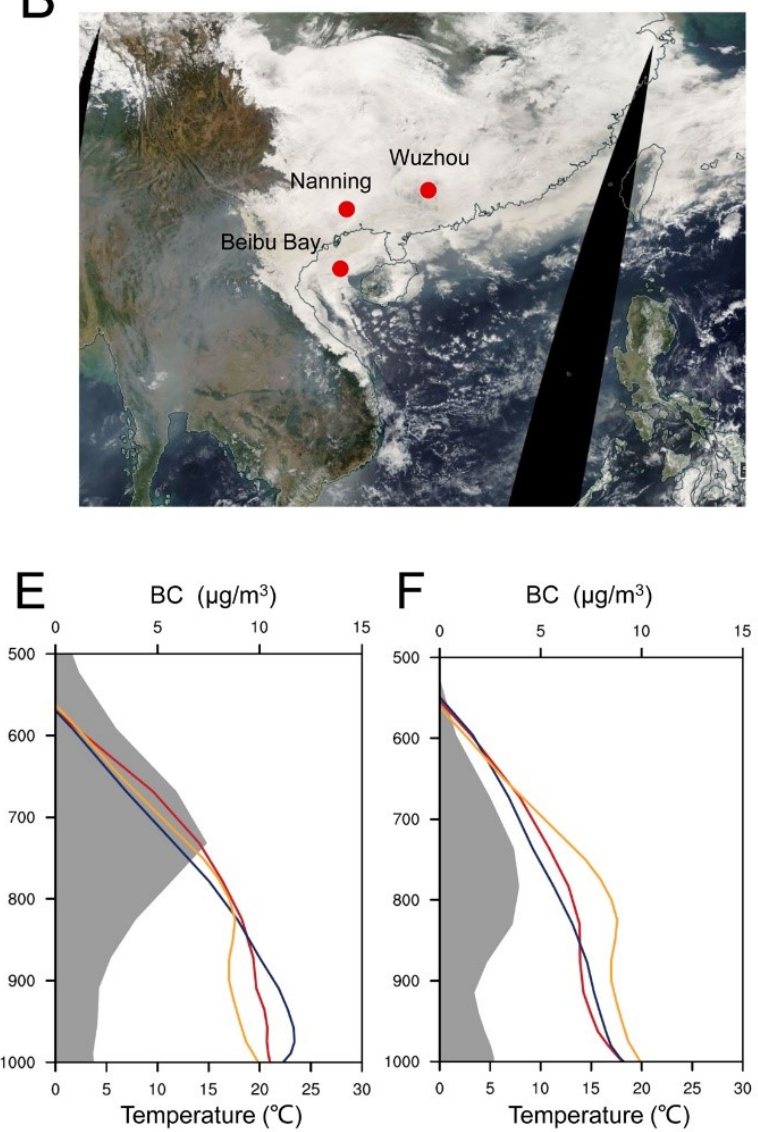

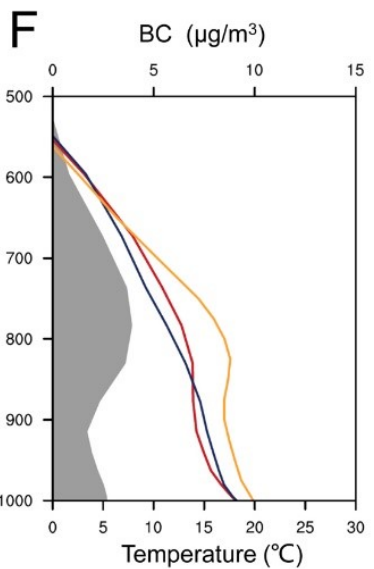

Fig. S15. Comparison of modeling and observational air temperature and clouds at ground station Nanning and Beibu Bay in March 2004. (A) Map showing the topography and location of Nanning, Wuzhou and Beibu Bay. (B) Same as (A) but showing the true-color-corrected reflectance images of 13 March 2004. Vertical distribution of BC concentration and air temperature from radiosonde measurements and different modeling scenarios for the 8 highest $(\mathbf{C})$ and 8 lowest (D) aerosol-PBL interaction days at Nanning. (E-F) Same as figs. S15C and S15D but over the ocean in Beibu Bay. 
A

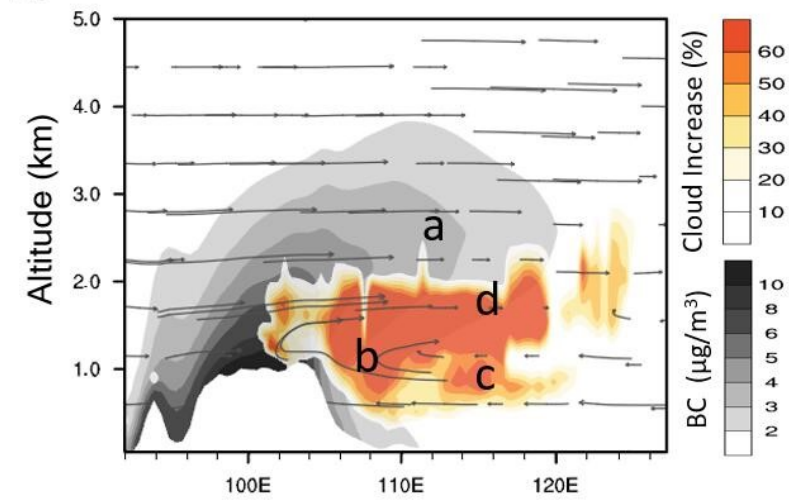

B

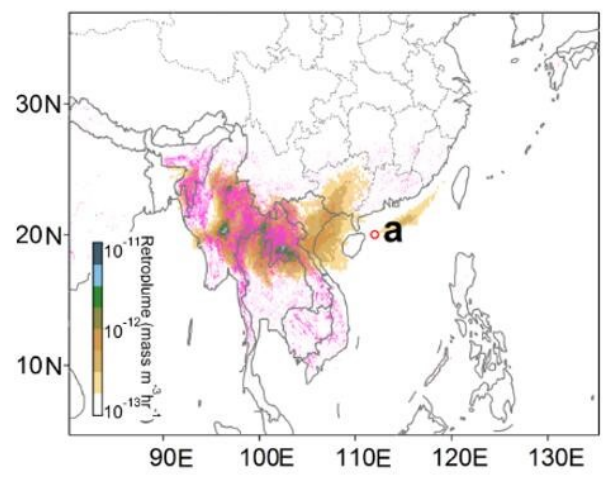

D

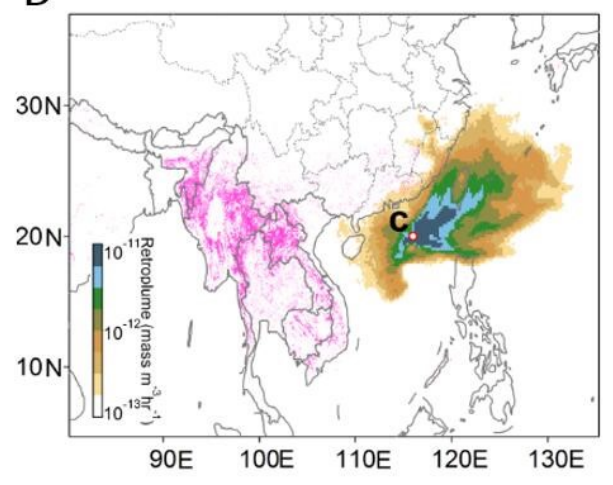

C

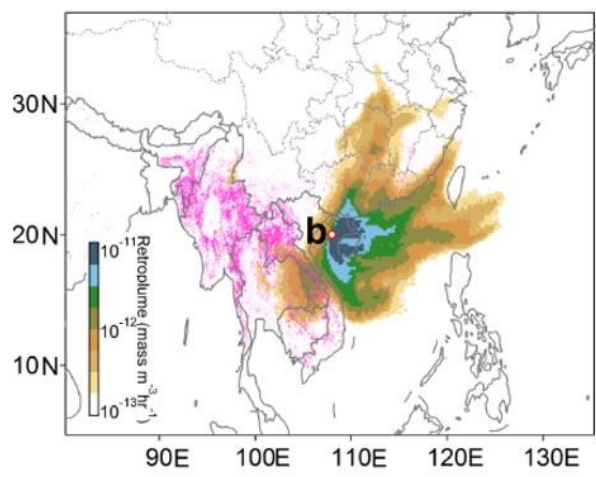

E

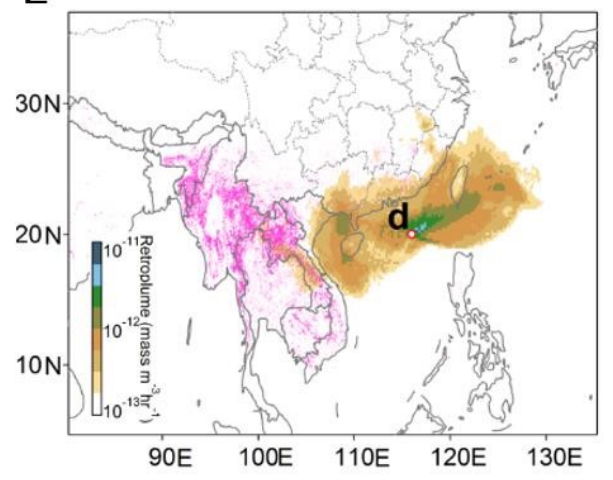

Fig. S16. Air mass origins for smoke and cloud along the BB plumes calculated by Lagrangian dispersion model. (A) averaged vertical cross-section of cloud difference and $\mathrm{BC}$ along the coastal line $\left(17^{\circ} \mathrm{N}-23^{\circ} \mathrm{N}\right)$ for the experiment EXP_FAR and EXP_exAR in March 2004 in Asia. Lagrangian dispersion modeling results shows air mass source regions for (B) Point a, (C) Point b, (D) Point c, and (E) Point d. Note: Method of LPDM are given in S6. 


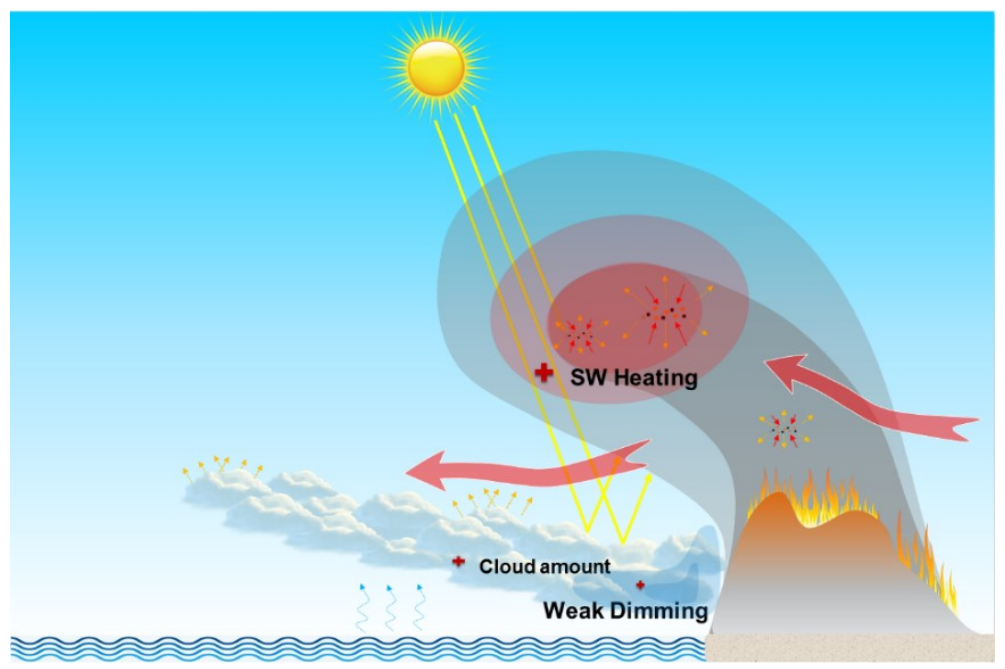

Fig. S17. Schematic figure showing mechanism of smoke - low cloud interaction in the Atlantic-Africa region. The shaded gray color indicates the $\mathrm{BB}$ plume. The red color along the plume shows shortwave heating by absorbing aerosols like BC. Shaded blue in the lee side of the plateau indicates dimming caused by aerosol-cloud-PBL interaction. 

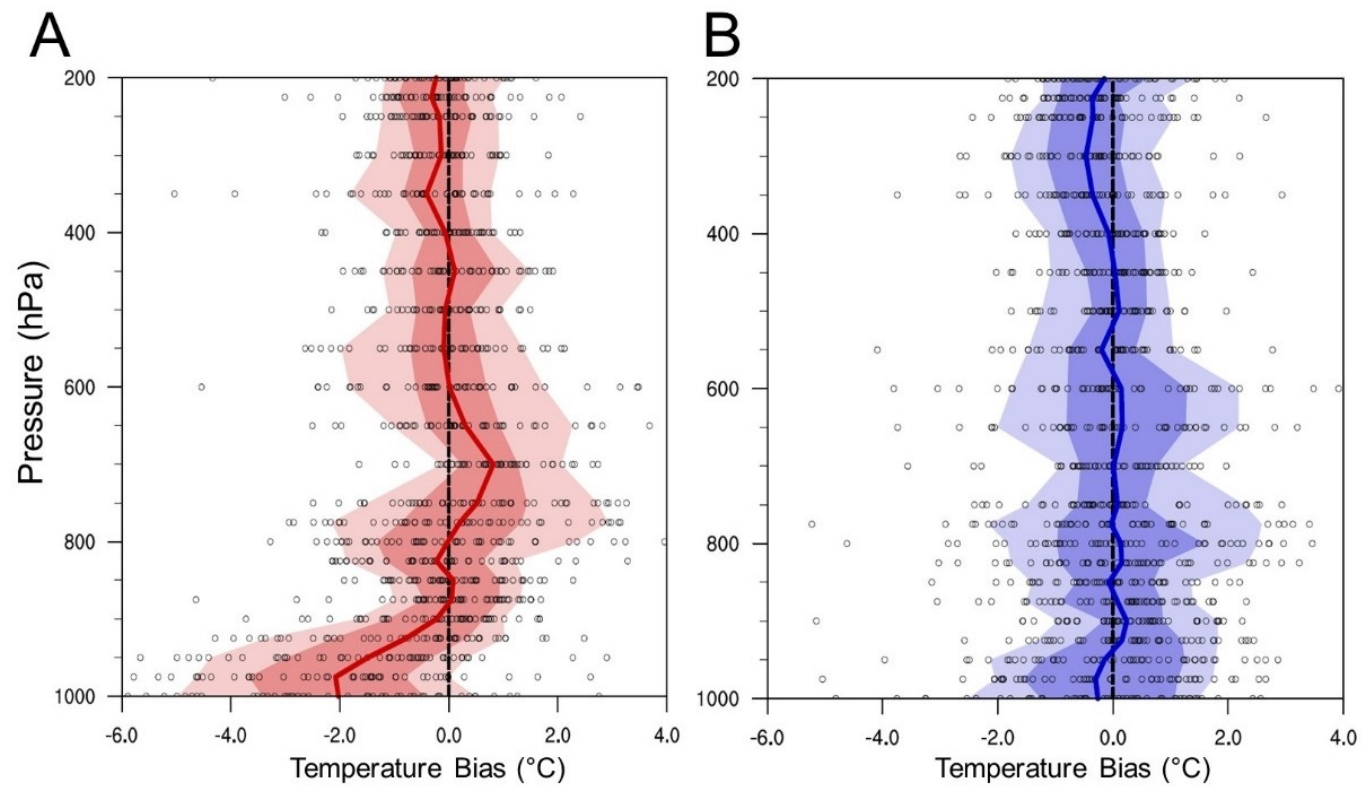

Fig. S18. Comparison of vertical profiles of OMR air temperature bias with/without influence from biomass burning. (A) Vertical profile of OMR air temperature for days with air masses at the altitude of $3 \mathrm{~km}$ influenced by biomass burning at Nanning and Wuzhou in Southwest China. (B) Same as (A) but for air masses less influenced by biomass burning. Note: 72-hr back trajectories at the altitude of $3 \mathrm{~km}$, calculated using HYSPLIT, are used to classify the influence from biomass burning in Southeast Asia. The 50 days with highest/lowest AOD are selected in the statistics here. 


\section{Table S1. Model configuration options and settings}

\begin{tabular}{|c|c|c|}
\hline \multicolumn{3}{|c|}{ Domain setting } \\
\hline Region & Asia & Africa \\
\hline Horizontal grid & $90 \times 170$ & $140 \times 210$ \\
\hline Grid spacing & $50 \mathrm{~km} \times 50 \mathrm{~km}$ & $50 \mathrm{~km} \times 50 \mathrm{~km}$ \\
\hline Vertical layers & 30 eta levels & 30 eta levels \\
\hline Center point & $105^{\circ} \mathrm{E}, 25^{\circ} \mathrm{N}$ & $13^{\circ} \mathrm{E}, 15^{\circ} \mathrm{S}$ \\
\hline Map projection & Lambert & Mercator \\
\hline \multicolumn{3}{|c|}{ Paramerization configuration } \\
\hline Long-wave radiation & & RRTMG \\
\hline Short-wave radiation & & RRTMG \\
\hline Cumulus parameterization & & Grell-Deveny \\
\hline Land-surface & & Noah \\
\hline PBL & & MYJ \\
\hline Microphysics & & Lin et al. \\
\hline Photolysis & & Fast-J \\
\hline Gas chemistry & & CBMZ \\
\hline Aerosol chemistry & & MOSAIC \\
\hline
\end{tabular}


Table S2. Emission inventories utilized in the WRF-Chem simulations

Emission source categories

Dataset

Anthropogenic activities

Biogenic emissions

Biomass burning emission
MIX Asian emission inventory

online caculated by MEGAN

caculated by 3BEM using burned area and thermal

Table S3. WRF-Chem parallel numerical experiment designs

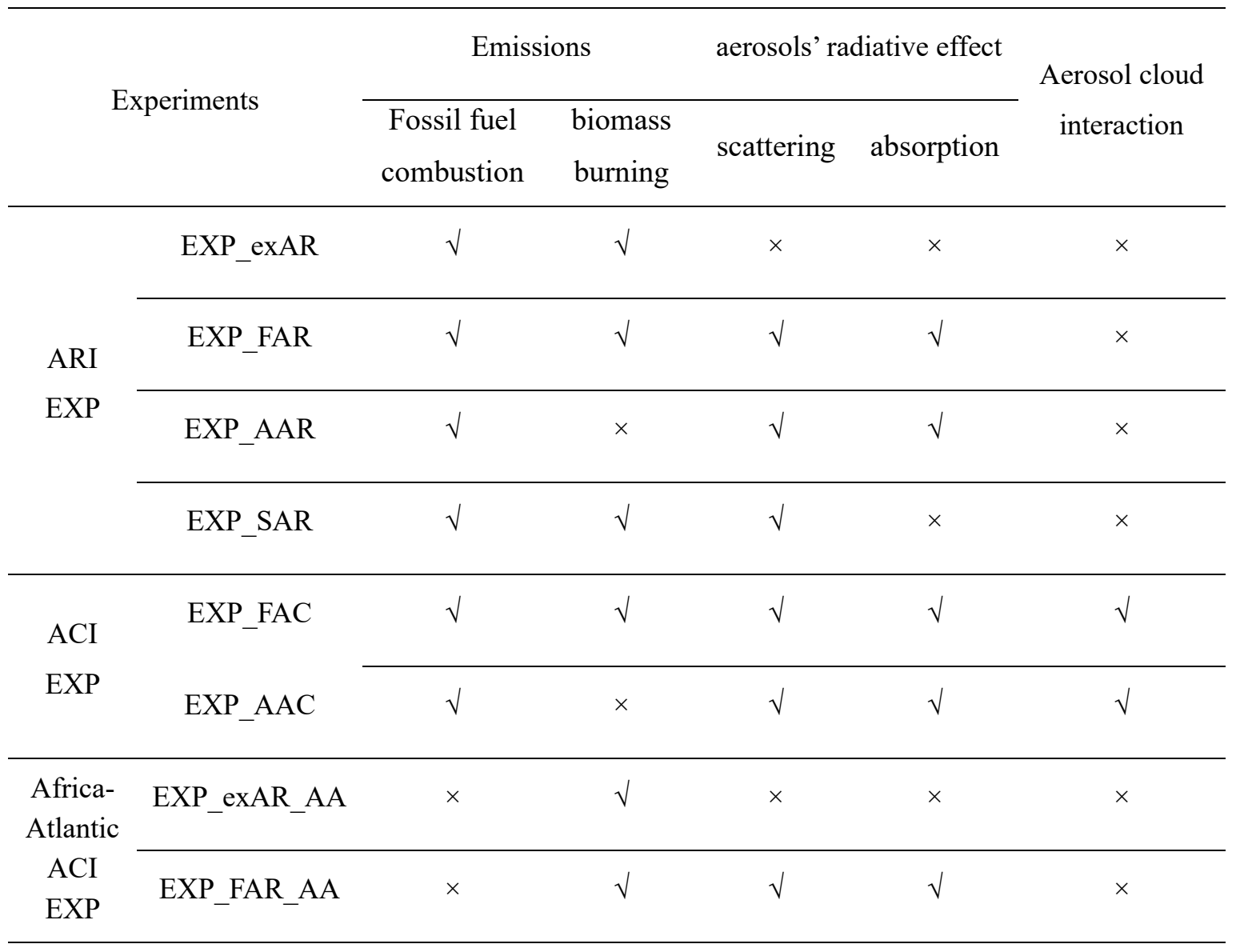


Table S4. Averaged carbon emission from biomass burning for four typical regions with intensive savanna and forest fires during 2000-2015.

\begin{tabular}{lcc}
\hline Domain $^{\mathrm{a}}$ & Period & Carbon emission (g C m \\
\hline Domain 1 -Center Africa & Nov.-Dec. & 18.48 \\
Domain2 -Southern Africa & Jul.-Aug. & 28.53 \\
Domain3 -This study & Mar.-Apr. & 8.90 \\
Domain4 -South America & Aug.-Sep. & 13.10 \\
\hline${ }^{a}$ Domain 1-4 are marked in fig. S4. &
\end{tabular}




\section{REFERENCES}

1. X. Huang, Z. L. Wang, A. J. Ding, Impact of Aerosol-PBL Interaction on Haze Pollution: Multiyear Observational Evidences in North China. Geophys Res Lett 45, 8596-8603 (2018).

2. E. Kalnay, M. Cai, Impact of urbanization and land-use change on climate. Nature 423, 528-531 (2003).

3. J. Wang, Z. W. Yan, P. D. Jones, J. J. Xia, On "observation minus reanalysis" method: A view from multidecadal variability. J Geophys Res-Atmos 118, 7450-7458 (2013).

4. L. Zhao, X. Lee, R. B. Smith, K. Oleson, Strong contributions of local background climate to urban heat islands. Nature 511, 216-219 (2014).

5. D. P. Dee et al., The ERA-Interim reanalysis: configuration and performance of the data assimilation system. Q J Roy Meteor Soc 137, 553-597 (2011).

6. A. J. Ding et al., Intense atmospheric pollution modifies weather: a case of mixed biomass burning with fossil fuel combustion pollution in eastern China. Atmos Chem Phys 13, 10545-10554 (2013).

7. C. O. Justice et al., The Moderate Resolution Imaging Spectroradiometer (MODIS): Land remote sensing for global change research. Ieee T Geosci Remote 36, 1228-1249 (1998).

8. Y. Kaufman, D. Tanré, "Algorithm For Remote Sensing Of Tropospheric Aerosol From Modis. Products: Mod04, Mod08," (ATBD ATBD-MOD-02, NASA Goddard Space Flight Center, Greenbelt, MD, 85pp, 1998).

9. L. Boschetti, D. Roy, A. Hoffmann, MODIS Collection 5 Burned Area Product-MCD45. User's Guide, Ver 2, (2009).

10. L. Giglio, J. Descloitres, C. O. Justice, Y. J. Kaufman, An enhanced contextual fire detection algorithm for MODIS. Remote Sens. Environ. 87, 273-282 (2003).

11. D. M. Winker, J. Pelon, M. P. McCormick, The CALIPSO mission: Spaceborne lidar for observation of aerosols and clouds. P Soc Photo-Opt Ins 4893, 1-11 (2003).

12. P. F. Levelt et al., The ozone monitoring instrument. Ieee T Geosci Remote 44, 1093-1101 (2006).

13. J. N. Thepaut, P. Courtier, G. Belaud, G. Lemaitre, Dynamical structure functions in a four-dimensional variational assimilation: A case study. Q J Roy Meteor Soc 122, 535-561 (1996).

14. P. Poli, S. B. Healy, D. P. Dee, Assimilation of Global Positioning System radio occultation data in the ECMWF ERA-Interim reanalysis. Q J Roy Meteor Soc 136, 1972-1990 (2010).

15. X. Huang, Z. L. Wang, A. J. Ding, Impact of Aerosol-PBL Interaction on Haze Pollution: Multiyear Observational Evidences in North China. Geophys Res Lett 45, 8596-8603 (2018).

16. L. Giglio, J. T. Randerson, G. R. van der Werf, Analysis of daily, monthly, and annual burned area using the fourth-generation global fire emissions database (GFED4). J Geophys Res-Biogeo 118, 317-328 (2013).

17. G. R. van der Werf et al., Global fire emissions and the contribution of deforestation, savanna, forest, agricultural, and peat fires (1997-2009). Atmos Chem Phys 10, 11707-11735 (2010).

18. M. Li et al., MIX: a mosaic Asian anthropogenic emission inventory under the international collaboration framework of the MICS-Asia and HTAP. Atmos Chem Phys 17, 935-963 (2017).

19. A. Guenther et al., Estimates of global terrestrial isoprene emissions using MEGAN (Model of Emissions of Gases and Aerosols from Nature). Atmos. Chem. Phys. 6, 3181-3210 (2006).

20. G. A. Grell et al., Fully coupled "online" chemistry within the WRF model. Atmos. Environ. 39, 6957-6975 (2005).

21. G. Grell, S. R. Freitas, M. Stuefer, J. Fast, Inclusion of biomass burning in WRF-Chem: impact of wildfires on weather forecasts. Atmos. Chem. Phys. 11, 5289-5303 (2011).

22. R. A. Zaveri, R. C. Easter, J. D. Fast, L. K. Peters, Model for simulating aerosol interactions and chemistry (MOSAIC). J. Geophys. Res.-Atmos. 113, D13204 (2008).

23. R. A. Zaveri, L. K. Peters, A new lumped structure photochemical mechanism for large-scale applications. J. Geophys. Res.-Atmos. 104, 30387-30415 (1999).

24. J. D. Fast et al., Evolution of ozone, particulates, and aerosol direct radiative forcing in the vicinity of Houston using a fully coupled meteorology-chemistry-aerosol model. J. Geophys. Res.-Atmos. 111, (2006).

25. J. C. Barnard, J. D. Fast, G. Paredes-Miranda, W. P. Arnott, A. Laskin, Technical Note: Evaluation of the WRF-Chem "Aerosol Chemical to Aerosol Optical Properties" Module using data from the MILAGRO campaign. Atmos. Chem. Phys. 10, 7325-7340 (2010).

26. A. Ding et al., Enhanced haze pollution by black carbon in megacities in China. Geophys Res Lett 43, 2873-2879 (2016). 
27. X. Huang et al., Effects of aerosol-radiation interaction on precipitation during biomass-burning season in East China. Atmos. Chem. Phys. 16, 10063-10082 (2016).

28. A. Darmenov, A. da Silva, The quick fire emissions dataset (QFED)-documentation of versions 2.1, 2.2 and 2.4. 32, 183 (2013).

29. S. Archer-Nicholls et al., Characterising Brazilian biomass burning emissions using WRF-Chem with MOSAIC sectional aerosol. Geosci. Model. Dev. 8, 549-577 (2015).

30. W. D. J. J. o. t. a. s. Collins, Parameterization of generalized cloud overlap for radiative calculations in general circulation models. 58, 3224-3242 (2001).

31. R. Pincus, C. Hannay, S. A. Klein, K. M. Xu, R. J. J. o. G. R. A. Hemler, Overlap assumptions for assumed probability distribution function cloud schemes in large - scale models. 110, (2005).

32. Y. Zhang et al., Impact of synoptic weather patterns and inter-decadal climate variability on air quality in the north China plain during 1980-2013. Atmos. Environ. 124, 119-128 (2016). 